NBER WORKING PAPER SERIES

\title{
HUMAN CAPITAL EFFECTS OF ANTI-POVERTY PROGRAMS: EVIDENCE FROM A RANDOMIZED HOUSING VOUCHER LOTTERY
}

\author{
Brian Jacob \\ Max Kapustin \\ Jens Ludwig \\ Working Paper 20164 \\ http://www.nber.org/papers/w20164 \\ NATIONAL BUREAU OF ECONOMIC RESEARCH \\ 1050 Massachusetts Avenue \\ Cambridge, MA 02138 \\ May 2014
}

This paper is part of a larger project with Greg Duncan, James Rosenbaum, Michael Johnson and Jeffrey Smith. Generous financial support was provided by the National Consortium on Violence Research, the Northwestern University / University of Chicago Joint Center for Poverty Research, the Smith Richardson Foundation, the William T. Grant Foundation, the Centers for Disease Control and Prevention (award U01-CE001631), a HUD Urban Studies Postdoctoral Fellowship (to Jacob), a Health Policy Investigator Award from the Robert Wood Johnson Foundation and visiting scholar awards from the Brookings Institution, Russell Sage Foundation, and LIEPP at Sciences Po (to Ludwig), and core operating support to the University of Chicago Crime Lab from the Joyce, MacArthur and McCormick foundations. We thank Roseanna Ander, John Baj, Lucy Mackey Bilaver, Ken Coles, Jack Cutrone, Christine Devitt, Megan Ferrier, Robert Goerge, Ron Graf, Anjali Gupta, Barry Isaacson, Bong Joo Lee, Charles Loeffler, Ernst Melchior, Mark Myrent, Stacy Norris, Jennifer O’Neil, Todd Richardson, and William Riley for their assistance in obtaining and interpreting the data used in this study. For helpful comments we thank Randall Akee, John DiNardo, Greg Duncan, Lisa Gennetian, Nora Gordon, Larry Katz, Jeffrey Kling, Katherine Magnuson, Ed Olsen, Katherine O'Regan, Marianne Page, Steve Raudenbush, Todd Richardson, Armin Rick, Lynn Rodgers, Mark Shroder, and seminar participants at the Chicago Federal Reserve, the NBER 2006 Summer Institute, the University of California, Berkeley, and the University of Chicago Harris School and Committee on Education for helpful comments. Thanks to Seth Bour, Eric Chyn, Megan Ferrier, Wei Ha, Jonathan Hershaff, Josh Hyman, Joe Peters, Sarah Rose, Matthew Smith, Elias Walsh, Jake Ward, Caroline Weber, Thomas Wei and Patrick Wu for excellent assistance working with the data. All opinions and any errors are our own. The views expressed herein are those of the authors and do not necessarily reflect the views of the National Bureau of Economic Research.

At least one co-author has disclosed a financial relationship of potential relevance for this research. Further information is available online at http://www.nber.org/papers/w20164.ack

NBER working papers are circulated for discussion and comment purposes. They have not been peerreviewed or been subject to the review by the NBER Board of Directors that accompanies official NBER publications.

(C) 2014 by Brian Jacob, Max Kapustin, and Jens Ludwig. All rights reserved. Short sections of text, not to exceed two paragraphs, may be quoted without explicit permission provided that full credit, including (C) notice, is given to the source. 
Human Capital Effects of Anti-Poverty Programs: Evidence from a Randomized Housing Voucher Lottery Brian Jacob, Max Kapustin, and Jens Ludwig

NBER Working Paper No. 20164

May 2014

JEL No. H53,H75,I38,J13,J24,R38

\begin{abstract}
$\underline{\text { ABSTRACT }}$
Whether government transfer programs increase the human capital of low-income children is a question of first-order policy importance. Such policies might help poor children if their parents are credit constrained, and so under-invest in their human capital. But it is also possible that whatever causes parents to have low incomes might also directly influence children's development, in which case transfer programs need not improve poor children's long-term life chances. While several recent influential studies suggest anti-poverty programs have larger human capital effects per dollar spent than do even the best educational interventions, identification is a challenge because most transfer programs are entitlements. We overcome that problem by studying the effects on children of a generous transfer program that is heavily rationed - means-tested housing assistance. We take advantage of a randomized housing voucher lottery in Chicago in 1997, for which 82,607 people applied, and use administrative data on schooling, arrests, and health to track children's outcomes over 14 years. We focus on families living in unsubsidized private housing at baseline, for whom voucher receipt generates large changes in both housing and non-housing consumption. Estimated effects are mostly statistically insignificant and always much smaller than those from recent studies of cash transfers, and are smaller on a per dollar basis than the best educational interventions.
\end{abstract}

Brian Jacob

Gerald R. Ford School of Public Policy University of Michigan

735 South State Street

Ann Arbor, MI 48109

and NBER

bajacob@umich.edu

Max Kapustin

Department of Economics

238 Lorch Hall

Ann Arbor, MI 48109

kapustin@umich.edu
Jens Ludwig

University of Chicago

1155 East 60th Street

Chicago, IL 60637

and NBER

jludwig@uchicago.edu

An online appendix is available at:

http://www.nber.org/data-appendix/w20164 


\section{INTRODUCTION}

The inter-generational elasticity of income in the United States is estimated to be 0.5 or 0.6, much higher than estimates for many other developed countries (Black and Devereux 2011). One hypothesis for why disadvantage is passed down from one generation to the next is that credit constraints cause poor parents to under-invest in children's human capital (Becker and Tomes 1986), which, if true, suggests a straightforward policy solution: transfer more resources to poor families. While the US devotes fewer resources to anti-poverty income transfers than other developed nations (Smeeding 2006), we nonetheless have the same desire for anti-poverty programs to enhance long-term productivity, and not simply alleviate short-term material need. In announcing the War on Poverty in 1964, for example, President Lyndon B. Johnson argued: "Very often a lack of jobs and money is not the cause of poverty, but the symptom. The cause may lie deeper in our failure to give our fellow citizens a fair chance to develop their own capacities, in a lack of education and training, in a lack of medical care and housing..."

Several recent influential studies suggest that anti-poverty programs may have an even higher return in educational outcomes than best-practice educational interventions, which if correct would imply there is no tradeoff to government between helping the poor in the short term and reducing inter-generational poverty in the long term. For example, Dahl and Lochner (2012) examine the effects of expanding the Earned Income Tax Credit (EITC) during the 1990s and estimate that an extra $\$ 1,000$ in family income (in 2013 dollars) ${ }^{1}$ raises children's test scores by 0.045 standard deviations (SD) overall, by 0.06 for black or Hispanic youth, and by 0.065 for males. Duncan, Morris, and Rodrigues (2011) estimate similar impacts using data from several welfare-to-work experiments. Milligan and Stabile (2011) find even larger impacts in Canada,

\footnotetext{
${ }^{1}$ Unless otherwise noted, all dollar amounts reported in this paper are in 2013 inflation-adjusted dollars. The estimates we report in text are slightly different from those reported in the original papers we cite because we have re-scaled their estimates to reflect the effect per $\$ 1,000$ in constant 2013 dollars.
} 
where $\$ 1,000$ in extra child-care benefits increases math scores by $0.05 \mathrm{SD}$ overall and $0.177 \mathrm{SD}$ for boys. Akee et al. (2010) study the effects of income received by low-income Native American families from the opening of a casino on tribal land in North Carolina. Their reducedform effect corresponds to an income change of $\$ 4,000$, and implies that an extra $\$ 1,000$ increases high school graduation by about 6 percentage points in the poorest families. Few if any educational interventions produce gains per dollar spent of these magnitudes.

However, the literature on the relationship between family income and child outcomes is controversial, owing largely to the challenge of disentangling causal effects from unobserved factors. Whatever makes it difficult for parents to succeed in the labor market may also adversely affect the development of their children. In that case, simply transferring resources to poor parents may not be enough to help poor children; what may be required is an intervention that targets the family attributes that drive the correlation between income and child outcomes, or a direct provision of educational services that compensate for what disadvantaged children are otherwise not receiving. The best empirical studies in this literature, such as those mentioned above, try to overcome this identification challenge by studying the effects of transfer programs that change the resources available to families. This strategy is complicated by the fact that most of America's largest transfer programs are entitlements available to all eligible people.

In this paper, we estimate the impact of an unusually generous US social programmeans-tested housing assistance—on important long-run outcomes of children. We take advantage of a large housing voucher lottery that was carried out in Chicago in July 1997, when for the first time in a dozen years the city began accepting applications again for the voucher program. ${ }^{2}$ A total of 82,607 eligible people applied; by way of comparison there were about

\footnotetext{
${ }^{2}$ We use "housing voucher" as shorthand for tenant-based rental subsidies. See Appendix A for a discussion.
} 
300,000 households in poverty in Chicago at the time. ${ }^{3}$ The number of applicants was far greater than the number of vouchers so applicants were randomly assigned to a wait list. We show below that this assignment was indeed random and greatly affected the chance a family was offered a voucher. ${ }^{4} \mathrm{We}$ are able to link applicants to a wide range of local, state, and federal administrative databases that allow us to measure outcomes for children in these families up to 14 years after the voucher lottery, including standardized test scores, high school graduation, arrest rates, earnings, and social welfare receipt as adults, and health outcomes from Medicaid claims data.

Our study focuses on the 90 percent of applicants living in unsubsidized private housing at the time of the lottery, for which a housing voucher represents a large, positive real income shock. The voucher allows these families to consume additional housing, but also allows them to consume more of other goods because it substantially reduces the fraction of their income they must contribute to rent. Our study thus answers a different question from that of the Moving to Opportunity (MTO) demonstration, which offered housing vouchers to families living in public housing. Families in MTO who were offered a voucher received a different form of housing assistance that allowed them to move to different neighborhoods, but did not directly change the resources available to families because the program rules for public housing and housing vouchers are identical in terms of the income eligibility limits and required rent contributions. ${ }^{5}$

Our study makes two important contributions. First, to the best of our knowledge, it is the first study of housing vouchers to use a credibly exogenous source of variation and to examine the long-term outcomes of a large sample of children using rich administrative data. There has

\footnotetext{
${ }^{3}$ In 2000 there were $\sim 2.9$ million people in Chicago, with an average of 2.67 people per household and a poverty rate in the city equal to 28.5 percent. http://www.brookings.edu/research/reports/2003/11/livingcities-chicago ${ }^{4}$ Shea's (2000, p. 182) paper on this topic notes that "perhaps future researchers will focus on more convincingly exogenous sources of parental income variation, such as lottery winnings or large changes in public transfers." We essentially combine both of these sources of variation.

${ }^{5}$ Results of the 5-year MTO follow are in Kling, Ludwig, and Katz (2005), Sanbonmatsu et al. (2006), and Kling, Liebman, and Katz (2007), while long-term results are in Sanbonmatsu et al. (2011) and Ludwig et al. (2011, 2012).
} 
been one other randomized study of housing vouchers (Mills et al. 2006), but it has only modest sample sizes and relies on parents' reports of children's outcomes (see Appendix B for more details). ${ }^{6}$ This dearth of evidence is surprising given the scale of low-income housing programs, which receive $\$ 40$ billion in federal spending each year-more than the total spending on Title I or Pell Grant programs in education, and over twice as much as is spent on cash welfare (Falk 2012). Despite this sizable budget, housing programs are very costly per recipient, so only onequarter of income-eligible families participate (Rice and Sard 2009). Families with children are a key target population and make up half of all participants in the voucher program.

Second, we shed new light on how means-tested transfer programs generally affect children's human capital and long-term life outcomes. Housing vouchers greatly increase the disposable cash available to families by reducing the amount they must contribute toward rent. The distinction between housing vouchers and cash transfers is further narrowed because poor families tend to spend a sizable share of their income on housing. Relative to most prior studies, ours includes a very large sample, a randomized research design, long-term follow-up, and the ability to examine multiple child outcomes (e.g., schooling, crime, and health). Moreover, the housing voucher we study is extremely generous. The average subsidy for our sample is over $\$ 12,000$, sizable compared to the average income of our sample $(\$ 19,000)$. The low average income of our sample also means we focus on the part of the income distribution where effects should be largest (Løken, Mogstad, and Wiswall 2012). We also use administrative data to

\footnotetext{
${ }^{6}$ Mills et al. (2006) has a sample of $\mathrm{N}=2,481$. Their confidence intervals do not allow them to reject effects of treatment on the treated (TOT) smaller than about 8 percent of a standard deviation (SD) for highest grade completed, about 25 percent SD for whether the child has ever been suspended or expelled in school, and about 30 percent SD for the behavior problems index (Mills et al. 2006, Exhibits 6.3 and 6.4). In terms of measuring outcomes, Theunissen et al. (1998) compare child and parent reports about the child's physical health, cognitive functioning, social functioning, and emotions and find correlations between 0.44 and 0.61 .
} 
measure outcomes, which have low rates of sample attrition and may be less susceptible to selfreporting error than surveys.

We find few statistically significant effects of housing vouchers on children's schooling outcomes, crime, or health, none of which are significant once we account for multiple hypothesis testing. Our estimates are also much smaller than what we would expect based on the results of recent studies of the effects of cash transfers. Even if we make the extreme assumption that additional housing consumption has no effect on children's outcomes, our confidence intervals rule out effects of income on outcomes like test scores for male children that are larger than one-third the size of those in Dahl and Lochner (2012) and one-eighth those in Milligan and Stabile (2011). The confidence interval around our estimate for income effects on high school graduation rates for males lets us rule out effects larger than about one-quarter of Akee et al. (2010). We get qualitatively similar findings if we restrict attention to just those infra-marginal families whose baseline housing consumption is equal to what is essentially the voucher's maximum rent; for these families receipt of a voucher is very close to being a pure cash transfer.

The main threat to internal validity with these results is from a slight treatment-control difference in migration out of the Chicago Public Schools, which could, in theory, bias our estimates of the education outcomes. However, as we show below, the amount of differential attrition is extremely small and a variety of sensitivity analyses suggest that any resulting bias is negligible. Moreover, we find no differential attrition from Illinois, which means that our crime and health outcomes (which come from state agency data) should not suffer from any such bias.

Our estimates also imply that extra cash transfers beyond the current level provided in the US are likely to have a smaller impact (per dollar) than the best-practice educational interventions explicitly designed to improve children's human capital. These findings are 
consistent with Currie's (2006) observation that in-kind programs targeted at specific outcome domains for poor children (in this case, education) are more effective than "a cash program that is not targeted at any particular outcome" (p. 3). Since the effect of income on children's outcomes is surely non-linear, our estimates do not imply that abandoning the existing system of social supports to children in the US would not harm their outcomes.

The next section discusses the program rules for housing vouchers and the candidate mechanisms through which receipt of a housing voucher might affect children's outcomes. Section III provides background on the 1997 housing voucher lottery that serves as the basis for our empirical analysis. Sections IV and V discuss our data and empirical strategy. Our results are in Section VI, while the limitations and implications of our results are in Section VII.

\section{CONCEPTUAL FRAMEWORK}

In this section, we first describe how the housing voucher program works, and then discuss how participation in the housing voucher program might influence childhood outcomes. A. Housing program rules

Housing vouchers subsidize low-income families to live in private-market housing. ${ }^{7}$ Eligibility limits for housing programs are a function of family size and income, and prioritize what the US Department of Housing and Urban Development (HUD) terms "very low-income households," with incomes for a family of four below 50 percent of the local median.

The maximum subsidy available to families is governed by the Fair Market Rent (FMR), which is partly a function of family size (larger families get a higher FMR to lease a larger rental unit). The FMR is also linked to the local metropolitan area's private-market rent distribution,

\footnotetext{
${ }^{7}$ This discussion is based on the excellent summary in Olsen (2003).
} 
usually set at the $40^{\text {th }}$ or $50^{\text {th }}$ percentile, and so varies over time and across areas. ${ }^{8}$

Families receiving vouchers are required to contribute towards rent 30 percent of their adjusted income, which under program rules can be substantially less than total income. The voucher covers the difference between the family's rent contribution and the lesser of the FMR or the unit rent. Voucher recipients can keep the subsidy for as long as they meet income and other eligibility requirements. ${ }^{9}$ For additional details about housing voucher rules, and how they interact with other social programs, see Appendix A.

B. Mechanisms through which housing vouchers might affect child outcomes

Receipt of a housing voucher may influence children's long-term outcomes in three possible ways: 1) by improving the quality of the housing conditions in which children reside; 2) by allowing parents to invest more in non-housing goods that may be developmentally productive for children; and 3) by reducing parental labor supply.

Figure I presents the budget constraint facing families that are trying to decide how to allocate income $I$ between the consumption of housing $(H)$ and other (non-housing) goods $(C)$, both normalized so that $P_{H}=P_{C}=1$. Consider a family at baseline with budget constraint $D J$ that, prior to receiving a voucher, locates at point $B$. After receiving a voucher subsidy with a cost to the government of $S$ (in our sample, on average $S=\$ 12,501$ ), their new budget constraint is given by $D U V L$, where $D-C_{V}$ is the rent contribution required by the voucher program. If the family leases a unit with rent up to the FMR, their new consumption bundle is at point $V$.

\section{Increased consumption of housing}

\footnotetext{
8 The FMR for a two-bedroom apartment in the Chicago area, in nominal dollars, equaled \$699 in $1994, \$ 732$ in 1997, and $\$ 762$ in 2000.

${ }^{9}$ Families using a voucher undergo annual examinations of their income and household composition by their local Public Housing Authority (PHA). These examinations determine the family's continued eligibility and establish the housing assistance payment (HAP) made by the PHA on the family's behalf. If a family's income rises to the point where their HAP is zero, they may continue to be enrolled for six months at which point, if the subsidy is not restored, their contract will terminate.
} 
The most obvious change for a family receiving a housing voucher is that their housing consumption increases substantially, from $H_{B}$ to $H_{V}$. For families in our study, average annual rent at baseline is $\$ 9,372$ (Table I), while the FMR for these families is on average $\$ 16,220$, so the maximum change in housing consumption from using a voucher is on average $H_{V}-H_{B}=$ $\$ 6,849$. This represents a 73 percent increase in housing consumption, or about 36 percent of the average baseline income of our families $(\$ 18,978)$.

Figure II gives some sense for the distribution of $H_{V}-H_{B}$ across families that leased up with a voucher, estimated as the rent recorded by the government the first time the household uses a voucher minus our estimate for their baseline (pre-lottery) rent. ${ }^{10}$ The distribution includes some negative changes in rent (housing consumption) from using a housing voucher, which could occur in the short run (as we are examining here) but should dissipate in the long run as housing consumption rises for all voucher recipients. ${ }^{11}$ If housing markets function at all well, we would expect higher-rent units to be either higher quality or located in more desirable neighborhoods. We show below that in practice families do not move to notably "better" neighborhoods, so most of the increase in housing consumption presumably comes from improved housing units as suggested by Mills et al. (2006). ${ }^{12}$

\footnotetext{
${ }^{10}$ Actual baseline rent is unobserved in our data. Instead, we assign to each family the average rent paid by demographically-similar households in their baseline census tract using a special tabulation of 2000 Census data from Chicago conducted for us by the Census Bureau. See Appendix D for details.

${ }^{11}$ In the short run, we could see declines in housing consumption (market rent) among those families who are living at baseline in apartments with rents close to or above the FMR. The housing voucher program provides families with a limited amount of time to find a new unit. Previous research suggests that not all landlords are willing to lease units to families with vouchers because of minimum housing quality restrictions (and inspections), paperwork, and other program requirements. A family with a baseline rent close to the FMR might move into a unit with lower rent in the short run because of these search constraints. In the long run, we expect families to adjust and re-optimize. ${ }^{12}$ Some observers have noted landlords are aware of the rent limits in the voucher program and some artificially raise the rent of a unit to meet the tenant's new ability to pay (Mallach 2007; Collinson and Ganong 2013). To the extent that this is the case, the estimates described above may overstate the increase in housing consumption. The welfare-to-work voucher study by Mills et al. (2006) suggests that even if this occurs to some degree, the net effect of housing voucher receipt may be an increase in unit quality or size. For example, the share of families in the control group that live in crowded housing conditions (more than one person per bedroom) at the time of their follow-up survey is about 39 percent, while the effect of voucher use (the TOT effect) is minus 22 percentage points
} 
A large correlational literature has found that at least some specific features of housing units, like presence of toxins or crowding, are associated with outcomes such as respiratory problems in children (Leventhal and Newman 2010). ${ }^{13}$ Few studies are able to control for unobserved family attributes that may confound estimates of housing effects on children. One exception is Currie and Yelowitz (2000), who use the sex composition of children in a family as an instrument for receipt of public housing and find that families in housing projects experience less overcrowding, and children, especially males, are less likely to be held back in school.

\section{Increased consumption of other goods}

Receipt of a housing voucher also allows a family to greatly increase their spending on non-housing goods (from $C_{B}$ to $C_{V}$ in Figure I) by reducing out-of-pocket spending on rent. Our sample spends on average $\$ 9,372$ on rent at baseline, over half their total income. ${ }^{14}$ Receipt of a voucher would let the average family in our sample reduce out-of-pocket spending on housing to $D-C_{V}=\$ 3,719$ (the average required rent contribution by the voucher program), resulting in average increased consumption of other non-housing goods of $C_{V}-C_{B}=\$ 5,653$, which equals 45 percent of the total voucher subsidy cost to the government and 29 percent of average baseline income for families. This represents a 59 percent gain in non-housing consumption. While a large body of research has studied the relationship between income and children's outcomes (e.g., Brooks-Gunn and Duncan 1997; Mayer 1997; see also Appendix B),

( $p<.05$ ); see Table 5.3 of Mills et al. 2006, p. 139. Similarly, the share of control group families reporting two or more housing problems is 13.5 percent, and the TOT is again about one-half that (minus 7 percentage points), although is not quite significant.

${ }^{13}$ For example, Fisk et al. (2007) find building dampness and mold to be associated with a 30-50 percent increase in respiratory and asthma-related outcomes, while Sharfstein et al. (2001) survey families on a Section 8 waiting list in Boston and find that nearly half of respondents report that their children suffered health problems, ranging from mental distress to asthma, as a consequence of substandard housing conditions. For a discussion of other studies of housing vouchers that mix together the different mechanisms examined here, see Appendix B.

${ }^{14}$ Nationwide, nearly two-thirds of extremely low-income renters, defined as those with incomes below 30 percent of area median income, spend half or more of their income on housing. Nearly 80 percent of these families spend at least 30 percent of their income on housing. Among all renter households, around one-quarter spend at least half their income on housing, and over one-half spend at least 30 percent of their incomes on housing (Bipartisan Policy Center 2013, p. 83). 
credibly identified estimates are rare. As Almond and Currie (2011) note, "it is...remarkably difficult to find examples of policies that increase incomes without potentially having a direct effect on outcomes." In addition to the research focused exclusively on academic outcomes of children (e.g., Dahl and Lochner 2012), Milligan and Stabile (2011) find that an extra child-care benefit resulted in improved physical health in males and mental health in females. Using variation in the rollout of the Food Stamp Program, Almond et al. (2011) find exposure to Food Stamps in the later stages of pregnancy increases birth weight.

Compared to a housing voucher of cost $S$ to the government, an equally costly cash transfer would lead a recipient to consume less housing and more non-housing goods (point $X$, in Figure I) compared to the voucher bundle $V$. Which of these two consumption bundles would be more developmentally productive for children depends on how developmentally productive housing is compared to whatever else parents would spend extra cash on instead. While voters must think housing is better than cash for at least some aspects of well-being (hence the provision of an in-kind rather than a cash benefit), it seems safe to assume that an upper bound for the effects of a housing voucher on children is the effect of a similarly costly cash transfer.

To better understand how our results compare to those from existing studies of cash transfers, we generate a set of lower bound estimates for the implied effect of income on child outcomes under the (probably extreme) assumption that a dollar of housing and a dollar of nonhousing consumption are equally helpful for children. We also calculate an upper bound for the effect of income on child outcomes by making an equally extreme assumption in the other direction, namely that additional housing has no impact on children's outcomes so that the effect of a housing voucher on children comes entirely from the change induced in non-housing consumption. Specifically, we estimate the size of the cash transfer that would lead to the same 
gain in non-housing goods as families get from receiving a voucher $\left(C_{V}-C_{B}\right.$ in Figure III, represented by $S^{*}$ ). The required cash transfer is larger than just the gain in non-housing consumption under the voucher, because when families get extra cash (e.g., through the EITC) they will likely choose to spend a portion of it on housing. We assume an income elasticity of housing of 0.35 (Mayo 1981; Polinsky and Ellwood 1979), which implies $S^{*}=\$ 6,377 .{ }^{15}$ This elasticity is towards the lower end of the range of estimates, which in turn yields a lower $S^{*}$ than would result from assuming a larger elasticity.

\section{Reduction in parental labor supply}

Housing vouchers may also affect child outcomes by reducing parental labor supply through both income effects (given the large resource transfer) and substitution effects (from the fact that they require families to contribute 30 percent of adjusted income towards rent). The net effect for our Chicago sample is to reduce work rates by about 4.6 percentage points, versus a control mean of 60 percent (Jacob and Ludwig 2012). Whether increased parental time with children increases or decreases human capital depends on how the developmental productivity of parental time compares with the alternative way children would have spent their time.

Compared to housing vouchers, other transfer programs may have different effects on parental labor supply depending on their design. If parents combine time and market goods to "produce" children's human capital, as in Becker (1965), then the effect of a transfer program on parental labor supply could change the way parents use extra cash to help their children and so moderate the effect of any cash transfer on children's outcomes (see Appendix C). This provides one explanation for why the results in Duncan et al. (2011), who study the effects of welfare-to-

\footnotetext{
${ }^{15}$ We can calculate $S^{*}$ in practice with the income elasticity of housing consumption $\left(e_{H, I}\right)$, baseline income $(I)$, together with consumption patterns before and after voucher receipt $\left(H_{B}, C_{B}\right.$, and $\left.C_{V}\right)$, using the fact that: $C_{V}-C_{B}=S^{*}-\left[\frac{S^{*}}{I} \times e_{H, I} \times H_{B}\right]$
} 
work programs that increase parental labor supply, differ from the effects we estimate of housing vouchers that slightly reduce parental labor supply. We return to this point in the discussion.

\section{THE CHICAGO HOUSING VOUCHER LOTTERY}

In July 1997, Chicago Housing Authority Corporation (CHAC) opened the city's voucher wait list for the first time in 12 years, and received a total of 82,607 applications from incomeeligible people. CHAC hired Abt Associates to randomly assign applicants to a waiting list in August 1997, and notified those in the top 35,000 positions of their wait list number. CHAC told these families on the "active wait list" that they would be offered a voucher within three years. CHAC informed the remaining applicants (lottery numbers 35,001 to 82,607 ) that they would not receive vouchers. ${ }^{16}$ By May 2003, after offering vouchers to 18,110 families from this wait list, CHAC was "over-leased," that is, had issued as many or more vouchers than it had funding to pay for, and essentially stopped offering any new vouchers. ${ }^{17}$

In the analysis that follows, we define our treatment group to be families offered vouchers by May 2003 (lottery numbers 1 to 18,110). The control group consists of applicants with lottery numbers above 35,000 who were told that they were not on the active wait list and would not get a voucher. We exclude families with lottery numbers between 18,110 and 35,000 from our primary sample because of their ambiguous treatment status. ${ }^{18}$

\section{DATA AND SUMMARY STATISTICS}

This section briefly describes the key data sources used in our analysis. For more detail

\footnotetext{
${ }^{16}$ Service of the July 1997 wait list was interrupted in August 1998, as CHAC was required to provide vouchers to a set of Latino families in response to a discrimination lawsuit against the City of Chicago. CHAC began to serve the 1997 wait list again at the start of 2000.

${ }^{17}$ The number of families offered vouchers per year (and the voucher utilization rate) was 1,540 (50.3 percent) in 1997; 3,085 in 1998 (50.1 percent); 2,631 in 2000 (43.6 percent); 5,733 (44.5 percent) in 2001; 4,674 (49.7 percent) in 2002; 446 (42.7 percent) in 2003.

${ }^{18}$ Families in this group could have been affected by the anticipation of receiving a voucher in the future, although since CHAC stopped giving out vouchers in 2003 these families may have given up hope of getting one. Appendix Table I shows that including this group does not change our main findings.
} 
on the data, including variable construction and matching, see Appendix D. The starting point for constructing our sample are the application forms for the 1997 wait list, which provide baseline information on the 82,607 adults and nearly 8,700 spouses who applied to CHAC for a housing voucher. The baseline application forms do not include the names of other household residents, so we use data from the Illinois Department of Human Services (IDHS) to determine who lived with the CHAC applicants in the period immediately before the wait list was opened.

Data on voucher utilization comes from HUD 50058 records, which families complete annually to verify program eligibility. Several methods were used to track residential locations for both treatment and control group families, which are then linked to census tract-level data.

To measure behavioral outcomes, we use longitudinal administrative data from a number of different government agencies. All of our administrative data matching uses only information from pre-randomization sources to preserve the strength of the experimental design. From the Chicago Public Schools (CPS) we obtained student-level school records for the academic years 1994-5 through 2010-11 that include test scores, grades, and enrollment or graduation status. We measure labor market involvement for youth and their parents using quarterly earnings data from the state unemployment insurance (UI) system through 2011:Q4. We measure social program participation of youth and parents from IDHS records through 2013:Q1. We measure criminal behavior using data from the Illinois State Police (ISP) that capture arrests through 2012:Q1.

Finally, we measure health outcomes using Medicaid claims data from the Center for Medicare and Medicaid Services (CMS) for the period from 1999:Q1 through 2008:Q4. One limitation of the Medicaid data is that most, but not everyone, in our study sample uses Medicaid. A second limitation is that we measure health outcomes only when a fee-for-service claim is filed, and some children in our sample receive benefits from a managed care 
organization $(\mathrm{MCO})$ that does not generate such claims (although there is no treatment-control difference in propensity to receive benefits from an $\mathrm{MCO}$ ). All results derived from claims that we present below are conditioned on being enrolled in fee-for-service care for six or more months during the academic year. Using this definition of enrollment, approximately $75 \%$ of our sample is ever enrolled at some point during 2000-2008, and 45\% are enrolled at a point in time, with at most a 1.4 percentage point treatment-control difference in enrollment rates as we show below. A third limitation is that claims data could confound access to care with health outcomes; we try to address this by focusing on conditions for which most people would seek care.

\section{Sample}

Table I presents summary baseline statistics for our main analysis sample-children of CHAC applicants living in private-market housing when they applied to the voucher lottery, separately for the 48,263 "control" children (whose families were not offered vouchers) and 18,347 "treatment" children (offered vouchers during 1997-2003) in our sample. We restrict our attention to children who were age 0-18 at the time of the 1997 lottery, and so do not include any children born subsequent to the lottery since fertility could be affected by voucher receipt.

Our program population is quite disadvantaged at baseline. Almost all families are headed by an unmarried, African-American woman, with nearly four out of five receiving some form of social-program assistance. The year before the lottery children have an average GPA of 1.5 on a 4 point scale, and attend schools that are overwhelmingly attended by other minority students who are eligible for free or reduced price lunch.

Comparing the baseline average characteristics of the control group (column 1 of Table I) with the treatment group (column 2) provides some evidence to confirm that the voucher lottery was indeed random. A few pair-wise comparisons are statistically significant, but an omnibus 
test of the null hypothesis that all of the treatment-control differences in baseline characteristics are jointly zero yields a p-value of $.49 .{ }^{19}$

\section{EMPIRICAL STRATEGY}

Given that the voucher lottery was random, a simple comparison of means between those offered vouchers and those who were not will provide an unbiased estimate of the effects of being offered a voucher, known as the "intention to treat" (ITT) effect. We discuss here how we estimate the ITT and the effects of actually using a voucher, and how we handle statistical inference with so many different outcomes.

\section{A. The Effect of Receiving a Voucher Offer}

Our data consist of a balanced panel where the unit of observation is the child-year. To facilitate comparison between education and crime data, we use academic years that span from Q3 of one year to Q2 of the following year. Our analysis period runs from 1997-98 through 2010-11, the last year for which we have most of our data sources. For child $i$ in year $t$, we use OLS to estimate the ITT effect on outcome $y_{i t}$ as:

$$
y_{i t}=\alpha+\beta_{1}\left(\text { PostOffer }_{i t}\right)+\beta_{2}\left(\text { PreOffer }_{i t}\right)+X \Gamma+\gamma_{t}+\varepsilon_{i t}
$$

PostOffer $_{i t}$ equals 1 if the family of child $i$ has been offered a housing voucher through the CHAC 1997 lottery in any period up to or including $t$, and zero otherwise. We also control for year effects, $\gamma_{t}$, and to increase precision we control for a set of baseline characteristics (see Appendix D). Standard errors are clustered by household (Bertrand et al. 2004). Identification of the ITT effect $\beta_{1}$ comes from a within-period comparison of the average outcomes of those

\footnotetext{
${ }^{19}$ We use the suest command in Stata to conduct an F-test for the joint significance of the treatment indicator, adjusting for the non-independence of baseline characteristics within households. This test essentially consists of regressing lottery numbers against all of the baseline characteristics shown in Table I in a way that accounts for the correlation among these baseline variables. An alternative approach is to cluster standard errors on baseline census tract rather than household ID; when we do this, the p-value is 0.44 . The set of baseline variables we examine in our omnibus test includes indicators for whether selected baseline measures are missing; when we replicate our omnibus tests excluding those missing indicators, the p-values (equal to 0.49 and 0.33 for clustering at the household or tract levels, respectively) still fail to reach traditional thresholds of significance.
} 
offered vouchers versus the control group. If there is heterogeneity in the effects of a voucher offer across people, calendar time, or duration of voucher receipt, then our ITT estimate is an average of the ITT effects across all post-voucher-offer person-years in our panel. We also include an indicator, PreOffer $_{i t}$, equal to 1 for people who were on the active wait list but had not been offered vouchers yet by year $t$, and equal to 0 otherwise. The coefficient provides evidence on whether families change their behavior in anticipation of getting a voucher. Note that this coefficient does not serve as a "randomization check," since it is estimated off of postrandomization treatment-control differences (recall our panel only includes post-lottery quarters).

The standard "education production function" in economics assumes children's outcomes are affected by the accumulated inputs they have experienced up to that point (see for example Hanushek 1979), which suggests that the effects of increased household resources may accumulate and grow over time. So also of interest for our analysis is to examine how voucher effects might change with the duration of voucher receipt. To do this, we use OLS to estimate the per-period ITT effect using the following event study-style specification:

$$
y_{i t}=\alpha+\sum_{k} D_{i t}^{k} \delta_{k}+X \Gamma+\gamma_{t}+\varepsilon_{i t}
$$

The key explanatory variables in this case are indicators $\left(D_{i t}^{k}\right)$ equal to 1 if, in period $t$, individual $i$ is $k$ years from when they were offered a voucher through the lottery $(k$ can take on positive and negative values). We present figures tracing out the time path of these effects below. The ITT effect could change over time because the behavioral response to leasing up with a voucher varies, or because the fraction or composition of families that have leased up with a voucher changes over time, or because of changes in economic, policy, or other social conditions. We explore some of these sources of heterogeneity below. B. The Effects of Using a Voucher 
The ITT estimate will not equal the effect of using a voucher because not all treatmentgroup families who were offered a voucher used them, and a small share of controls received a housing voucher through some other special allocation during our study period (between 5 and 8 percent, as shown below). ${ }^{20}$ Under the assumption that the voucher offer does not have an impact on those who choose not to take it, we can use two-stage least squares with randomized voucher offers as an instrument to estimate the effects of using a voucher with equations (3) and (4). The dependent variable in equation (3) is an indicator for whether household $i$ utilized a voucher provided by any source (the CHAC lottery or some other allocation) by or in period $t .^{21}$

$$
\begin{aligned}
& \text { Leased }_{i t}=\alpha+\theta_{1} \text { PostOffer }_{i t}+\theta_{2} \text { PreOffer }_{i t}+X \Gamma+\gamma_{t}+\varepsilon_{i t} \\
& y_{i t}=\eta+\pi_{1} \text { Leased }_{i t}+X \Pi+\mu_{t}+v_{i t}
\end{aligned}
$$

Because a small share of families assigned to the bottom of the 1997 CHAC wait list wind up receiving vouchers through some other program during our study period, our estimate for $\pi_{1}$ captures the local average treatment effect on those induced to use a voucher by their CHAC wait list position (Angrist, Imbens, and Rubin 1996). ${ }^{22}$ As a benchmark for judging the size of our IV estimates, we present what Katz, Kling, and Liebman (2001) call the control complier mean (CCM), or the average outcome for controls who would have used vouchers had

\footnotetext{
${ }^{20}$ Among the other sources of housing vouchers during our study period was the HOPE VI program, through which HUD financed CHA to demolish some of the city's most notorious housing projects; some of the displaced families were offered vouchers through a special allocation. Other families on the CHAC wait-list could have received vouchers from another program because they contained a disabled member, or were at risk for having parents separated from children without a change in housing status, or were Latino and so received vouchers as a result of litigation by Latinos United against the CHA that interrupted service of the 1997 wait-list for several years.

${ }^{21}$ Under this definition a family that uses but then gives up their voucher does not become "untreated," under the assumption that a child's outcomes are a function of current and past investments. In practice, over half of households who lease up with a CHAC voucher remain leased-up after eight years (Appendix Figure I). The results do not change much if we instead define the endogenous explanatory variable of interest as "using a housing voucher in period $t . "$

${ }^{22}$ If voucher effects instead vary by how long a family is leased up, then $\pi_{1}$ captures the LATE for those who lease up for a longer period of time due to treatment group assignment, so long as we are willing to assume that control group cross-overs would have been leased up for at least as much time had they been assigned to treatment. If we instead calculated our IV estimate using a more conservative assumption that all treatment group voucher users lease up for a longer period of time than if they had been assigned to the control group, our IV estimate will capture the effects of treatment-on-the-treated (TOT).
} 
they been assigned to the treatment group. We calculate this using the formula from Heller et al. (2013) to account for the presence of control crossovers.

Table II shows there is a large "first-stage" relationship between being offered a housing voucher through the CHAC lottery and whether the child's family used a voucher. Our estimate for $\theta_{1}$ is nonetheless less than 1 ; despite the long wait list for housing vouchers, many families offered vouchers do not wind up using them. Reasons include the fact that many apartments have rents above the FMR limit, some landlords may avoid renting to voucher families, ${ }^{23}$ and families offered vouchers have a limited time (usually 2 to 4 months) to use the voucher to lease a unit. In the top panel, which presents results for our full analysis sample, column 1 shows the coefficient on the PostOffer indicator from estimating equation (3). Around 7 percent of controls used a voucher, and assignment of a wait list number below 18,110 increased voucher lease-up rates by 48 percentage points. The F-test statistic equals 5,835. The voucher take-up rate we report here is consistent with those reported in previous studies. ${ }^{24}$ The results are qualitatively similar if we estimate a cross-section regression for whether a child's family ever uses a voucher while CHAC was issuing vouchers (1997-2003), as in column 2, or if we focus on using a voucher from the 1997 CHAC lottery specifically (columns 3 and 4).

\section{Comparison to Estimated Effects of Cash Transfers}

While the ITT and TOT estimates tell us about the effects of the housing voucher program on children's outcomes, we are also interested in comparing our results to the broader

\footnotetext{
${ }^{23}$ Some landlords may avoid renting to voucher families because of the paperwork requirements, the program's minimum housing quality standards (which must be verified by an inspection, although failed units can be modified and re-inspected), and a previous rule that has since been abolished that limited the ability of landlords to turn away future voucher applicants ("take one, take all").

${ }^{24}$ By comparison, Finkel and Buron (2001) study 48 public housing agencies around the country and find an overall voucher lease-up rate of 69 percent in 2000, with lower rates in big cities such as New York (57 percent) and Los Angeles (47 percent). In the Gautreaux mobility program in Chicago, around 19 percent of the public housing families who signed up used a voucher (Rubinowitz and Rosenbaum 2000, p. 67). Kling, Liebman, and Katz (2007) report that in the MTO experiment, 47 percent of families assigned to the experimental (low-poverty) voucher group lease-up, as do 60 percent of those assigned to the regular Section 8 voucher group. See also Olsen (2003).
} 
literature on cash transfers, in which results are typically reported in terms of benefits per $\$ 1,000$ of additional income. We do this under different assumptions about whether housing is as productive for children as non-housing consumption to bound the estimated effects.

We first assume that a dollar of housing and a dollar of non-housing consumption are equally productive for children's outcomes. To do this we replace Leased $_{i t}$ as the endogenous explanatory variable in equations (3) and (4) with Leased $_{i t} \times S_{i}$, where $S_{i}$ is a measure of the size of the voucher subsidy family $i$ was eligible for calculated using baseline (pre-lottery) data, and shown in 2013 dollars (see Appendix E). This rescales the TOT by the average $S$ in our sample $(\$ 12,501)$, so $\pi_{c a s h} \approx \frac{\pi_{1}}{S}$. Dividing the TOT by an upper bound for the plausible cash equivalent value of a voucher provides a lower bound estimate for $\pi_{c a s h}$.

We then assume that housing consumption has no developmentally productive effects on children's human capital, so that any effect on children's outcomes caused by the voucher operates entirely by increasing non-housing consumption. As described above (see Figure III), we estimate that the average cash transfer that would generate the same gain in non-housing consumption as families in our sample experience from receipt of a housing voucher equals $S^{*}=$ $\$ 6,377$. Dividing the TOT by a lower bound for the plausible cash equivalent value of a voucher yields an upper bound estimate for $\pi_{c a s h}$. In our tables we also show an even more extreme upper bound that assumes both that housing is unproductive for children and that the income elasticity of housing equals zero. In this case we rescale the TOT by the increase in non-housing consumption families experience from voucher receipt, equal on average in our sample to $\Delta C=$ $C_{V}-C_{B}=\$ 5,653$.

D. Multiple Hypothesis Testing 
The final issue we discuss is how to account for the large number of outcomes we can examine with our data, and how to manage the risks of both false positives and false negatives. Our approach follows what we believe to be the "best practice" (Kling, Liebman, and Katz 2007; Anderson 2008; Schochet et al. 2008) although, as Anderson (2008) shows, relatively few studies in the social sciences make such adjustments.

First, we pre-specify a limited set of outcomes and subgroups for a main, confirmatory analysis. We focus on four outcomes: (i) high school graduation; (ii) a composite of math and reading achievement scores; (iii) the social cost of crimes committed by youth, an "importanceweighted" index that assigns a dollar value representing the cost to society to each youth arrest based on estimates from the literature, ${ }^{25}$ and (iv) emergency department and inpatient hospital admissions. Given prior evidence that social policy effects may differ by gender (Kling, Ludwig, and Katz 2005; Kling, Liebman, and Katz 2007; Anderson 2008), we examined impacts separately by gender. We also look separately at children $0-6$ versus $6-18$ years of age at the time of the lottery, given the possibility of declining developmental plasticity by age (Shonkoff and Phillips 2000; Knudsen et al. 2006) and the findings of Morris et al. (2004) and Duncan et al. (2011) that income only impacts achievement in young children. Second, in addition to reporting per comparison p-values from standard t-tests, we also control for the false discovery rate (FDR), or the proportion of null-hypothesis rejections that are Type I errors or "false positives," using the two-step procedure from Benjamini, Krieger, and

\footnotetext{
${ }^{25}$ We follow the approach in Kling, Ludwig, and Katz (2005), discussed further in Appendix D. In Appendix Tables V-VIII, we conduct sensitivity analyses that examine what happens to our estimates if we trim the dollar value for the social costs of homicide (which tends to be much higher than other offenses and so can drive estimates using this sort of dollar-weighted index), setting its value to twice that of the next-highest crime, or set the estimated social costs of drug possession offenses to zero. Our appendix tables also show results separately for arrests by offense type: violent, property, drug, and other. The results for these different measures are almost never statistically significant, with the exception of arrests to female youth aged 6-18 at baseline, for whom there is some indication that housing voucher receipt may be associated with an increase in arrests for violent crimes.
} 
Yekutieli (2006). Because the TOT is basically just a re-scaled version of the ITT point estimate and standard error, with a similar t-statistic, we report the FDR-adjusted p-values for the ITT.

Since ours is a standard "multiple end points" problem that arises when comparing some alternative program to status quo (see Benjamini and Hochberg 1995), where the decision about which is preferable will depend on the whole set of outcomes being compared and not on the significance of any single outcome, we think the FDR is the most appropriate adjustment for multiple comparisons. For completeness, we also control for the family-wise error rate (FWER), or the probability of making any Type I error, calculated using a free step-down re-sampling method. ${ }^{26}$ The FWER is the more conservative of the two adjustments, so the fact that we find few statistically significant impacts even with our focus on the FDR strengthens our conclusions about the limited effect of even large resource transfers on children's outcomes.

\section{RESULTS}

In this section, we present our findings on how housing vouchers affect child outcomes.

We then discuss how these results inform the broader literature on income transfers. Finally, we explore a variety of mediating mechanisms through which vouchers might operate.

\section{A. Effects of Housing Vouchers on Children's Outcomes}

Table III presents the impact estimates for our primary outcome measures. Even if we initially ignore multiple testing issues and focus on pairwise error rates, just one out of twelve

\footnotetext{
${ }^{26}$ We use a bootstrap resampling technique that simulates data under the null hypothesis (Westfall and Young 1993; Anderson 2008). Within each permutation, we randomly re-assign treatment indicators with replacement and estimate program impacts on all of our primary outcome measures across our different sub-groups. By repeating this 2,500 times, we create an empirical distribution of t-statistics that allows us to compare the actual set of t-statistics we find to what we would have found by chance under the null. We maintain the original sampling frame in each iteration, assigning the same number of pseudo-treatment and pseudo-control youth as in our original sample. This technique preserves the correlational structure and underlying distributions of our data, providing the adjusted probability we would observe our results by chance given our data and the number of tests we run. Rather than use a single p-value adjustment for all the outcome measures, we use a free step-down procedure to adjust the p-value on each outcome separately. The idea is that once a null hypothesis has been rejected, it is removed from the family of hypotheses being tested (thus increasing the power of the remaining tests). We then calculate a new adjusted p-value with the bootstrapped empirical distribution of t-statistics for only the remaining tests, providing a more powerful adjustment than setting all $\mathrm{p}$-values to the same minimum value.
} 
estimates is significant at the usual 5 percent threshold (social costs of crime committed by females), and another is significant at the 10 percent cutoff (achievement test scores for males age 0-6 at baseline). If we account for multiple testing by controlling for either the FDR or FWER, then none of these estimates are statistically significant at conventional cutoffs. ${ }^{27}$

Given our reliance on mostly city- or state-level administrative records, one threat to the internal validity of our estimates comes from the possibility of differential attrition. Table IV shows that there is no difference in the treatment versus control group in the fraction of quarters living outside of IL between 1997 and 2005. A recent update of this data allowed us to get information on the location of households in 2012. Again, we see no statistically significant difference in the chance of living in Illinois; our 95 percent confidence interval lets us rule out an ITT effect any larger than about 4 percentage points. ${ }^{28}$ This result suggests that our estimates for the majority of our outcomes, all of which rely on state data, should not suffer from any bias.

Such outcomes include arrest records, public assistance receipt and earnings.

However, Table V shows that younger children in our treatment group are slightly more likely to be in the Chicago Public School (CPS) system in any given academic year. The ITT is 3 (2) percentage points for boys (girls) age 0-6 at baseline. In theory, this differential attrition might bias our achievement estimates for the young children in our sample. ${ }^{29}$ In practice, we think that any bias is negligible. First, even after attrition, children in the treatment and control groups are nearly identical on the comprehensive set of baseline observables presented earlier (see Appendix Table II). Second, because there is little difference between treatment and control children in the rates with which they ever appear in the CPS system, we re-estimate our ITT

\footnotetext{
${ }^{27}$ Performing the calculation of FDR-adjusted p-values separately by gender does not affect our results.

${ }^{28}$ Unfortunately, we were not able to obtain address histories from 2005-2012 for this sample of households.

${ }^{29} \mathrm{We}$ find that treatment children are slightly more likely to be enrolled in Medicaid over our sample period, which is consistent with earlier evidence that the voucher offer led to a small increase in social program participation (see Jacob and Ludwig 2012).
} 
model replacing any missing student test scores with a student's last observed score, which yields estimates very similar to those reported in Table III. We also calculate bounds using the approach from Lee (2009), which suggest that our results for graduation impacts are robust to differential attrition, although these bounds are very wide for test scores (Appendix Tables III and IV). A final point to note is that differential treatment-control attrition is identical for boys and girls (Table V). Yet vouchers appear to have (if anything) a more positive impact on boys, as seen in Table III, suggesting differential attrition is unlikely to be driving the result. ${ }^{30}$

These results appear to generalize to a broader set of outcomes as well. Appendix Tables V to VIII show ITT and TOT estimates of a variety of additional outcome measures in each of our domains, in the spirit of exploratory analyses. These results suggest vouchers had few detectable impacts on children's outcomes. Quantile regression estimates suggest that there were no consistent and significant estimates across different parts of the ability distribution. ${ }^{31}$

It is possible that any voucher effect increases with duration of voucher receipt, which could be missed by our main estimates. Figure IV shows ITT estimates and confidence intervals by time since offer for achievement test scores and social costs of crime committed by youth. We do not see much trend over time in any of these outcomes or across analytic samples.

\footnotetext{
${ }^{30}$ Of course, it is possible that the attrition process operated differently across genders despite the identical rates of attrition, though this seems unlikely.

${ }^{31}$ One might imagine that the intervention had different impacts across different points in the ability distribution. To explore this possibility we estimated quantile regressions of the test score. To simplify the estimation, we collapse the panel to a single observation per student, averaging student test scores for all post lottery periods. We then estimate a cross-sectional regression where the key independent variable is an indicator for being in the treatment group. We show estimates of the effect of being offered a voucher (i.e., ITT estimates) on the $10^{\text {th }}, 25^{\text {th }}, 50^{\text {th }}, 75^{\text {th }}$ and $90^{\text {th }}$ quantiles of the test score distribution. The results suggests that, to the extent that there is any effect on math test scores for pre-school age boys, the results may be concentrated at the higher end of the distribution. While the estimates are not terribly precise, we see no significant effects below the $75^{\text {th }}$ percentile, where the impact is 0.0526 SD (Appendix Table IX).
} 


\section{B. Implications for Effects of Cash Transfers and Family Income on Child Outcomes}

The results described above suggesting that even large transfers to families through housing vouchers do not generate many detectable changes in children's outcomes provide an initial indication that our data do not seem consistent with recent studies suggesting large effects of cash on children's outcomes. This section sharpens those comparisons by using the IV methods described above to directly compare effects on children per $\$ 1,000$ of extra income.

Table VI presents our IV estimates for the effect of an extra $\$ 1,000$ (in 2013 dollars) on each of our primary outcomes for each of our gender-age analysis samples. To help get some initial sense for the magnitudes, control means are in column 2. Column 3 presents our lowerbound IV estimate for the effects of each extra $\$ 1,000$ in cash on children's outcomes, assuming that a marginal dollar spent on housing is as valuable for children's outcomes as a marginal dollar spent on non-housing consumption, and so re-scales our TOT estimate by the full subsidy cost to the government $(\$ 12,501$ on average). Column 4 presents one of our upper-bound estimates, assuming that housing has no effect on children, by scaling the TOT using the value of the cash transfer that would provide families with the same-sized increase in consumption of non-housing goods that they get from receiving a housing voucher ( $\$ 6,377$ on average). Column 5 is an even higher upper-bound, and assumes that housing has no effect on children and that the income elasticity of housing is zero. It divides the TOT by an even smaller assumed cash equivalent to a voucher, equal to just the gain in non-housing consumption from voucher receipt (\$5,653 on average).

The results in Table VI indicate that even the top of the confidence intervals around our upper-bound estimates are still much smaller than the impacts on children's outcomes per $\$ 1,000$ reported in the recent literature. For example, the largest estimate implied by our data for the 
impact of an extra $\$ 1,000$ on young boys' achievement test scores is roughly .011 SD with a standard error of .006. Our confidence intervals enable us to rule out an effect of cash on test scores that is any larger than $0.022 \mathrm{SD}$, about one-third the estimated effect for boys from DahlLochner and one-eighth the estimated effect for boys in Milligan-Stabile (Figure V). ${ }^{32}$

The same pattern is true if we look at other outcomes as well, such as high school graduation rates (Figure VI). As noted above, Akee et al. (2010) use data from a casino opening on an Indian reservation and estimate that an extra $\$ 1,000$ of income increases high school graduation rates by about 6 percentage points. Our largest IV estimates, from column 5 of Table VI, suggest an effect per $\$ 1,000$ of extra income on high school graduation rates for boys equal to 0.6 percentage points, with a standard error of 0.4 percentage points; for girls the point estimate and standard error both equal about 0.4 percentage points. Put differently, our estimates let us rule out effects on high school graduation rates per thousand dollars larger than about 1.4 percentage points, or about one-quarter the size of the estimate from Akee et al. (2010).

An alternative approach for using our data to estimate the effect of cash transfers on children is to essentially estimate the reduced-form effect of a voucher on children's outcomes for the subset of families in our sample for whom receipt of a housing voucher is essentially a cash transfer. In Table VII we present results for families whose baseline housing consumption is so high relative to the voucher's rent ceiling (FMR)—either within $\$ 50$ per month of the FMR, or actually greater than the FMR — that receipt of a housing voucher is unlikely to result in additional housing consumption and therefore acts like a pure cash transfer. ${ }^{33}$

\footnotetext{
${ }^{32}$ Impacts for achievement test scores for girls are in Appendix Figure II; our estimate is again much smaller than that of Dahl and Lochner, but not so different from that of Milligan and Stabile, who find little effect of cash on test scores for girls in their paper.

${ }^{33}$ The key difference being that there are more bureaucratic hurdles involved in utilizing the voucher than in cashing a check. To use a housing voucher to lease a given apartment, the unit must pass inspection by the local housing authority and the landlord must agree to rent the unit to the voucher-holder. Continued use of a voucher requires
} 
Table VII shows that the results for these families are qualitatively similar to the IV estimates for the full sample we report in Table VI. For example, the estimates in column 6 of Table VII suggest that $\$ 1,000$ of additional income for young boys is associated with an increase of $0.017 \mathrm{SD}$ (standard error 0.015) on standardized achievement scores, compared to an upperbound IV point estimate for the full sample in Table VI of 0.011 (standard error 0.006). The 95 percent confidence interval around our estimate for these families is significantly wider than when we use the full sample, since focusing just on those with baseline rents close to the voucher rent cap reduces the size of the analysis sample by 90 percent. But even these less precise estimates still let us rule out an effect on test scores any larger than about two-thirds that for boys from Dahl-Lochner and one-fourth that of Milligan-Stabile. Similarly, the point estimate for high school graduation for males in our infra-marginal sample in Table VII is no larger than about 0.5 percentage points per $\$ 1,000$ of extra income with a standard error of 1.3 , compared to an IV estimate for the full sample that is never larger than about 0.6 percentage points with a standard error of 0.4. These estimates let us rule out high school graduation effects larger than about onehalf the size of the estimates presented in Akee et al. (2010).

One candidate explanation for why our estimates are so different from what we would expect based on previous studies of the effects of cash transfers on children is that there are families in our study sample who at baseline are homeless or doubled up, for whom receipt of a housing voucher actually increases their out-of-pocket spending on rent and so reduces their consumption of other (non-housing) goods. This would lead our IV estimate to understate the true effects of cash on child outcomes, because we would be dividing the TOT estimate by too large a number (an overstated figure for the gain in non-housing consumption). The best estimate

submitting to annual reexamination of household income and composition. Termination of a voucher may also result in the case of drug-trafficking or violent criminal activity. 
we have found for the share of poor families that are doubled up is about 6 percent. ${ }^{34}$ Many of these families may be paying housing expenses even though they are doubled up. Even if we make the extreme assumption that all of them pay zero rent at baseline, then about 6 percent of our sample would experience a reduction in consumption of non-housing goods equal to the amount of the required voucher rent payment, which averages $\$ 3,800$ for our study sample. This would reduce the average gain in non-housing consumption for our study sample by just $(.06 \times \$ 3,800) \approx \$ 230$. The share of our study sample that is both doubled-up and paying little or no rent at baseline and would need to be implausibly large in order to explain why our results are so different from those of recent studies of cash transfer programs.

Another reason that we might expect differences in estimates across studies involves differences in samples and study contexts (i.e., issues of external validity). One way to assess this possibility is to look at the non-experimental relationship between income and child outcomes across studies. Using data from the year prior to the lottery in our study sample, we estimate an OLS regression as close to the one in Table 2, Panel A, Column 1 of Dahl and Lochner (2012) as we can. As shown in Figure VII, our OLS estimate of the relationship between $\$ 1,000$ of income and student achievement is if anything somewhat larger than that reported in Dahl and Lochner (2012). If the relationship between family income and child outcomes is non-linear, then one explanation for the difference in OLS estimates is that our

\footnotetext{
${ }^{34}$ The Homelessness Research Institute estimates that there are 800,000 families with incomes 125 percent of the poverty line or less that are doubled up (http://b.3cdn.net/naeh/97569cfc8f6ecf741f_vhm6bhzcg.pdf), while the Census Bureau estimates that in 2012 there were 12.5 million families with incomes equal to or below 125 percent of the poverty line. These two figures together imply that about 6 percent of poor and near-poor families are doubled up. (Presumably at least some of those families are contributing something to rent even though they are doubled up; unfortunately we are not aware of any reliable estimates of rent contributions by this population.) While there are higher estimates in the literature for the number of people who are doubled up in America, these higher estimates include large numbers of adult children living with their parents, or grandparents living with their children and grandchildren, which are not relevant for our applicant pool of low-income families with children. For example, estimates from the Census Bureau suggest that about 19 percent of all households containing children under age 18 lived in shared households with other adults (i.e. doubled up). (Personal communication between Laryssa Mykta, Census Bureau, and Patrick Wu, University of Chicago, July 17, 2013).
} 
sample is more disadvantaged than theirs. If this is the case, then we would expect our main estimates that exploit the randomized experimental design of our voucher lottery to be larger than those Dahl and Lochner present using their IV design. What we actually find is the opposite. C. Mediating Mechanisms

Why do such large resource transfers as generated by our housing voucher lottery not generate larger gains in children's test scores? One possibility is that parents dedicate additional resources to goods other than those that are widely thought to translate into improved children's outcomes. Mayer (1997, p. 99) shows that, in general, when low-income families get extra income they tend to spend it on things like food, shelter, clothes, health care, and transportation, all of which are only weakly correlated with child outcomes. We do not have detailed consumption or expenditure data for our specific sample of families, but with the administrative data sources we do have available to us we can at least try to narrow down what how families are allocating their additional resources.

Table IV showed that families do not seem to be "spending" much of their extra income moving to neighborhoods with features that previous research suggests may be developmentally productive for children, such as lower rates of poverty, racial segregation, or crime. This table reports ITT and TOT effects of voucher receipt on different measures of neighborhood of residence for the 10 percent random sub-sample of CHAC applicants for whom we have passive tracking address data from 1997 through 2005, and in 2012. Few of the effects are statistically significant and the point estimates are always small in relation to the control means. In Appendix Table X, we show the results are not qualitatively different if we focus instead on address information captured by Illinois social program data, which provide annual address information but at the cost of covering only those families who are receiving some form of social assistance. 
Because neighborhood "quality" is capitalized into housing prices, our results imply that families must be taking most of their increased housing consumption in the form of better housing units rather than "better" neighborhoods.

Tables VIII and IX show that families also do not seem to devote much of the additional resources they receive from a housing voucher on improved school quality for their children or reduced school mobility (frequent changes of a child's school attended are a major problem in urban districts; see NRC/IOM 2010). Of course the most obvious way for families to access higher-quality schools is to move residences, so at some level these results may not be surprising given our finding above that families are not spending additional resources on changing neighborhood "types." But because Chicago is a district with a fair amount of school choice, families in principle could use the additional resources provided by vouchers to move their children to higher-quality schools even without moving residences by, for example, buying a car.

Another mechanism through which vouchers may affect children is via their involvement in the formal labor market and participation in social programs during young adulthood. Wilson (1996) argues that formal work can provide structure for daily routines, while Heller (2014) argues that teen employment teaches young people social-cognitive skills. If voucher receipt reduces youth labor supply, it could potentially offset the beneficial effects of extra income on outcomes among the adolescents in our sample. But this explanation turns out not to be important in practice; Appendix Tables V through VIII show no statistically significant effects of vouchers on youth employment, as measured by quarterly UI earnings data from Illinois. There is a small increase in participation rates in a several social programs like Food Stamps.

VII. DISCUSSION 
The question of whether transferring additional resources to poor families beyond what is currently provided by existing social safety net programs will help poor children is of first-order importance for public policy, given the $\$ 411$ billion the U.S. spent on safety net programs in 2012 (including $\$ 40$ billion on means-tested housing programs). ${ }^{35}$ The U.S still has over 16 million children (22 percent) living in poverty. ${ }^{36}$ Theory yields an ambiguous answer about the effects of such transfers on children's human capital and long-term life outcomes. Credit constraints may cause poor parents to underinvest in children's human capital. Alternatively, the widely documented correlation between poverty and child outcomes could reflect that whatever limits parents' success in the labor market may also limit the outcomes of their children.

Identifying the causal relationship between income and children's outcomes has proved challenging despite a wealth of empirical work in economics and other social sciences on this question. Our study re-examines this question using a very large, randomized housing voucher lottery carried out in Chicago in 1997. Housing vouchers are an unusually generous social program by American standards, and unlike most other major social programs are rationed—the key to identification in our paper.

We find no statistically significant impacts of receiving a housing voucher on any of the primary children's outcomes we examine here, once we adjust our statistical inference to account for multiple-testing issues. Nor do we see any trends over time to suggest these impacts increase with the duration of voucher receipt. The findings are somewhat surprising given how generous vouchers are, but are nonetheless broadly consistent with those of Mills et al.'s (2006) randomized trial study of providing housing vouchers to families eligible for or receiving TANF. Their study does not find consistent effects on children's outcomes, although they rely on parent

\footnotetext{
${ }^{35} \mathrm{http}: / / \mathrm{www} . \mathrm{cbpp}$. org/cms/?fa=view\&id=1258

${ }^{36}$ http://www.nccp.org/topics/childpoverty.html
} 
reports on children's outcomes (which can be error-prone), have a fairly modest sample size $(2,481$ follow-up surveys were completed), and follow families for just four years. We build on those findings by generating much more precise zeros using administrative data on 66,610 separate youth with outcomes in multiple domains — schooling, crime, health - measured over a period of 14 years.

The one potential source of uncertainty about the internal validity of our estimates comes from slightly reduced rates of migration out of Chicago or Illinois by our voucher treatment group compared to our control group. This generates missing data, since we measure outcomes using administrative records from city and state government agencies. We do not believe that the amount of bias caused by differential attrition is likely to be large, since the amount of extra "missingness" for our treatment group tends to be small, just a few percentage points at most. Further, there are no treatment-control differences in the likelihood of ever appearing in any of our data systems during the post-lottery period, which means that fairly simple imputation methods like using the most recent valid value for missing observations should work reasonably well in our application. This approach yields similar results to our main findings.

Our results, if they are correct, also imply effects of cash transfers on children's outcomes that are much smaller than those reported in several recent influential papers on this topic. We recognize that housing vouchers and cash transfers are not equivalent. But we can generate an upper bound for the effect of a cash transfer on children's outcomes using our data by making the extreme assumption that additional housing consumption has no effect on children's outcomes. In other words, we assume the only "active ingredient" for children's outcomes from getting a housing voucher is the reduction in out-of-pocket spending towards rent families have to make, which on average for our sample equals $\$ 5,653$ - about 45 percent of the total voucher 
subsidy cost to the government and 29 percent of average baseline income for families. Receipt of a voucher increases non-housing consumption for our families by 59 percent.

Our estimates let us rule out effects of cash transfers on children's outcomes any larger than about one-third those reported by Dahl and Lochner (2012) or about one-eighth those reported by Milligan and Stabile (2011) for boy's test scores, or about one-fourth those reported by Akee et al. (2010) for high school graduation among poor families. The difference in results does not seem to be due to the fact that we are relying on a Chicago-specific sample while these other papers use data from other contexts; applying OLS to our data yields an estimate of the income-student achievement relationship similar to or even slightly larger than the estimate reported by Dahl and Lochner (2012). The results also do not seem to hinge on any of the assumptions we make in using the voucher lottery to instrument for a cash transfer. We find qualitatively similar results applying our "reduced form" voucher approach to infra-marginal families whose baseline rents are close to the voucher rent ceiling, for whom receiving a housing voucher is close to receiving a pure cash transfer. One explanation for the differences in these results is the difference in research designs used across the different studies.

A different explanation is required for reconciling our findings with those of Duncan et al. (2011), who analyze data from several welfare-to-work experiments and find impacts of extra income of similar size to those reported by Dahl and Lochner (2012). We think our results are not in conflict with those of Duncan et al., given that they are estimated using a different “treatment." Housing vouchers, like any lump-sum cash transfer or social program that reduces benefit amounts as families receive more earned income, generate some slight reduction in parental labor supply. So our study answers the question of what happens when children receive 
more income together with more parental time. The welfare-to-work experiments studied by Duncan et al. (2011) provide children with more income together with less parental time.

As we argue in Appendix C, if children's human capital is produced through a mix of parental time and market goods, then the effect of any transfer program on parental labor supply is an important moderator of its effect on children's outcomes, shaping how parents spend extra income. For example, while Mayer (1997) finds that most low-income parents devote extra income to things like food, shelter, clothes, health care, and transportation, Duncan et al. find in their welfare-to-work experiments that mothers of preschool-age children, who are pushed to work far more hours, wind up devoting a sizable share of their extra income to buying centerbased care. Support for the view comes from findings by Morris, Gennetian, and Duncan (2005), who note that much of the relationship between income and child outcomes in the welfare-towork experiments is explained away after controlling for use of early childhood center care. Additional support for our hypothesis comes from the fact that only pre-school-age children show gains in outcomes from extra income in their study; elementary school children show few gains while adolescents actually show a reduction in test scores when parents get more income (Morris, Duncan, and Rodriguez 2004; Morris, Duncan, and Clark-Kauffman, 2005).

Our results are consistent with those of Mayer (1997), who concludes there is "little reason to expect that policies to increase the income of poor families alone will substantially improve their children's life chances" (p. 14). More promising may be strategies to directly change whatever else it is about home environments that affects children's outcomes, or perhaps more promising still, educational interventions that provide children with whatever they are not able to receive from their households and neighborhoods. Figure VIII, for example, compares the effects on boy's test scores per $\$ 1,000$ cash implied by our data to the gains in test scores from 
several leading educational interventions: Head Start; class size reduction in grades K-3 from the Tennessee STAR experiment; and the Success for All school-reform model, all of which have point estimates that imply larger effects per dollar than the intervention we study (recognizing the uncertainty bands around these estimates are sometimes wide and overlapping). One general concern with this sort of comparison is that cash transfers are what Mayer calls a "multipurpose" intervention that can change multiple outcomes. But our results suggest the impacts of extra cash appear to be small across multiple key domains such as schooling, crime, and health.

Our findings do not imply that cash transfers or other anti-poverty programs like housing vouchers are not worth supporting. These programs surely improve the well-being of families in a variety of critical ways. Nor do our results imply that eliminating the existing social safety net in the US would not harm children's outcomes, since the effects of income on children's outcomes are surely non-linear, and our data come from estimating the effects of adding income supplementary to existing safety net supports. But our results do suggest, consistent with the arguments in Currie (2006), that if the goal is to improve children's human capital outcomes, rather than provide families with larger cash transfers and hope those translate into what children need, a better strategy may be to invest in interventions that provide what children need directly. 


\section{REFERENCES}

Akee, Randall K. Q., William E. Copeland, Gordon Keeler, Adrian Angold, and E. Jane Costello (2010). “Parents’ Incomes and Children’s Outcomes: A Quasi-Experiment Using Transfer Payments from Casino Profits.” American Economic Journal: Applied Economics, 2(1): 86-115.

Almond, Douglas, and Janet M. Currie (2011). "Human Capital Development before Age Five." Handbook of Labor Economics, 4: 1315-1486.

Almond, Douglas, Hilary W. Hoynes, and Diane Whitmore Schanzenbach (2011). "Inside the War on Poverty: The Impact of Food Stamps on Birth Outcomes." The Review of Economics and Statistics, 93(2): 387-403.

Anderson, Michael L. (2008). "Multiple Inference and Gender Differences in the Effects of Early Intervention: A Reevaluation of the Abecedarian, Perry Preschool, and Early Training Projects.” Journal of the American Statistical Association, 103(484): 1481-95.

Angrist, Joshua D., Guido W. Imbens, and Donald B. Rubin (1996). "Identification of Causal Effects Using Instrumental Variables.” Journal of the American Statistical Association, 91(434): 444-55.

Becker, Gary S. (1965). “A Theory of the Allocation of Time.” Economic Journal, 75(299): 493-517.

Becker, Gary S., and Nigel Tomes (1986). "Human capital and the rise and fall of families." Journal of Labor Economics, 4(3): S1-S39.

Benjamini, Yoav, and Yosef Hochberg (1995). "Controlling the False Discovery Rate: A Practical and Powerful Approach to Multiple Testing." Journal of the Royal Statistical Society, Series B, 57(1): 289-300. 
Benjamini, Yoav, Abba M. Krieger, and Daniel Yekutieli (2006). "Adaptive linear step-up procedures that control the false discovery rate." Biometrika, 93(3): 491-507.

Bertrand, Marianne, Esther Duflo, and Sendhil Mullainathan (2004). "How Much Should We Trust Differences-In-Differences?” Quarterly Journal of Economics, 119(1): 249-276.

Bipartisan Policy Center Housing Commission (2013). “Housing America’s Future: New Directions for National Policy.” Washington, D.C. Downloaded from http://bipartisanpolicy.org/sites/default/files/BPC_Housing Report_web_0.pdf.

Black, Sandra and Paul Devereux (2011). "Recent developments in intergenerational mobility." In Handbook of Labor Economics, Edited by Orley Ashenfelter and David Card. North Holland Press; Elsevier.

Borman, Geoffrey D., and Gina M. Hewes (2002). “The Long-Term Effects and CostEffectiveness of Success for All.” Educational Evaluation and Policy Analysis, 24(4): 24366.

Brooks-Gunn, Jeanne, and Greg J. Duncan (1997). "The Effects of Poverty on Children." The Future of Children, 7(2): 55-71.

Collinson, Robert, and Peter Ganong (2013). "Incidence and Price Discrimination: Evidence from Housing Vouchers.” Working paper, W13-7. Joint Center for Housing Studies, Harvard University.

Currie, Janet M. (2006). The Invisible Safety Net: Protecting the Nation's Poor Children and Families. Princeton, NJ: Princeton University Press.

Currie, Janet M., and Aaron Yelowitz (2000). "Are public housing projects good for kids?" Journal of Public Economics, 75(1): 99-124.

Dahl, Gordon B., and Lance Lochner (2012). “The Impact of Family Income on Child 
Achievement: Evidence from the Earned Income Tax Credit." American Economic Review, 102(5): 1927-56.

Duncan, Greg J., Pamela Morris, and Chris Rodrigues (2011). “Does Money Really Matter? Estimating Impacts of Family Income on Young Children's Achievement with Data from Random-Assignment Experiments.” Developmental Psychology, 47(5): 1263-1279.

Falk, Gene (2012). "Low-Income Assistance Programs: Trends in Federal Spending." In Congressional Research Service (CRS), House Ways and Means Committee, United States Congress. Available at http://greenbook.waysandmeans.house.gov/sites/greenbook.waysandmeans.house.gov/files/20 12/documents/RL41823_gb.pdf.

Finkel, Meryl, and Larry Buron (2001). Study on Section 8 Voucher Success Rates: Volume I: Quantitative Study of Success Rates in Metropolitan Areas. Cambridge, MA: Abt Associates.

Fisk, William J., Quanhong Lei-Gomez, and Mark J. Mendell (2007). "Meta-analyses of the associations of respiratory health effects with dampness and mold in homes." Indoor Air, 17(4): 284-96.

Hanushek, Eric A. (1979). "Conceptual and empirical issues in the estimation of educational production functions." Journal of Human Resources, 14(3): 351-88.

Heller, Sara (2014). “The Effects of Summer Jobs on Justice-Involved Youth.” In progress. Heller, Sara, Harold Pollack, Roseanna Adler, and Jens Ludwig (2013). "Preventing Youth Violence and Dropout: A Randomized Field Experiment.” NBER Working Paper 19014. Jacob, Brian A., and Jens Ludwig (2012). “The Effects of Housing Assistance on Labor Supply: Evidence from a Voucher Lottery.” American Economic Review, 102(1): 272-304.

Katz, Lawrence F., Jeffrey R. Kling, and Jeffrey B. Liebman (2001). "Moving to Opportunity in 
Boston: Early Results of a Randomized Mobility Experiment." Quarterly Journal of Economics, 116(2): 607-54.

Kling, Jeffrey R., Jeffrey B. Liebman, and Lawrence F. Katz (2007). “Experimental Analysis of Neighborhood Effects." Econometrica, 75(1): 83-119.

Kling, Jeffrey R., Jens Ludwig, and Lawrence F. Katz (2005). “Neighborhood Effects on Crime for Female and Male Youth: Evidence from a Randomized Housing Voucher Experiment." Quarterly Journal of Economics, 120(1): 87-130.

Knudsen, Eric I., James J. Heckman, Judy L. Cameron, and Jack P. Shonkoff (2006).

“Economic, neurobiological, and behavioral perspectives on building America's future workforce." Proceedings of the National Academy of Sciences, 103(27): 10155-62.

Lee, David (2009). “Training, Wages, and Sample Selection: Estimating Sharp Bounds on Treatment Effects.” Review of Economic Studies, 76(3): 1071-1102.

Leventhal, Tama, and Sandra Newman (2010). "Housing and child development." Children and Youth Services Review, 32: 1165-74.

Løken, Katrine V., Magne Mogstad, and Matthew Wiswall (2012). "What linear estimators miss: The effects of family income on child outcomes." American Economic Journal: Applied Economics, 4(2): 1-35.

Ludwig, Jens, Lisa Sanbonmatsu, Lisa A. Gennetian, Emma Adam, Greg J. Duncan, Lawrence F. Katz, Ronald C. Kessler, Jeffrey R. Kling, Stacy Tessler Lindau, Robert C. Whitaker, and Thomas W. McDade (2011). "Neighborhoods, obesity and diabetes: A randomized social experiment." New England Journal of Medicine, 365(16): 1509-19.

Ludwig, Jens, Greg J. Duncan, Lisa A. Gennetian, Lawrence F. Katz, Ronald C. Kessler, Jeffrey R. Kling, and Lisa Sanbonmatsu (2012). "Neighborhood effects on the long-term 
well-being of low-income adults." Science, 337(6101): 1505-10.

Ludwig, Jens, and Deborah A. Phillips (2008). "Long-Term Effects of Head Start on LowIncome Children." Annals of the New York Academy of Sciences, 1136(1): 257-68.

Mallach, Alan (2007). "Landlords at the Margins: Exploring the Dynamics of the One to Four Unit Rental Housing Industry." Working paper, RR07-15. Joint Center for Housing Studies, Harvard University.

Mayer, Susan E. (1997). What Money Can't Buy: Family Income and Children's Life Chances. Cambridge, MA: Harvard University Press.

Mayo, Stephen K. (1981). “Theory and estimation in the economics of housing demand.” Journal of Urban Economics, 10: 95-116.

Milligan, Kevin, and Mark Stabile (2011). "Do Child Tax Benefits Affect the Well-Being of Children? Evidence from Canadian Child Benefit Expansions." American Economic Journal: Economic Policy, 3(3): 175-205.

Mills, Gregory, Daniel Gubits, Larry Orr, David Long, Judie Feins, Bulbul Kaul, Michelle Wood, Amy Jones \& Associates, Cloudburst Consulting, and the QED group (2006) The Effects of Housing Vouchers on Welfare Families. Washington, DC: U.S. Department of Housing and Urban Development, Office of Policy Development and Research.

Morris, Pamela A., Greg J. Duncan, and Christopher Rodrigues (2004). “Does Money Really Matter? Estimating Impacts of Family Income on Children's Achievement with Data from Random-Assignment Experiments.” Working paper.

Morris, Pamela A., Greg J. Duncan, and Elizabeth Clark-Kauffman (2005). "Child well-being in an era of welfare reform: The sensitivity of transitions in development to policy change." Developmental Psychology, 41(6): 919-32. 
Morris, Pamela A., Lisa A. Gennetian, and Greg J. Duncan (2005). "Effects of Welfare and Employment Policies on Young Children: New Findings on Policy Experiments Conducted in the Early 1990s." Society for Research in Child Development, 19(2): 3-17.

National Research Council and Institute of Medicine (2010). Student Mobility: Exploring the Impact of Frequent Moves on Achievement: Summary of a Workshop. A. Beatty, Rapporteur. Committee on the Impact of Mobility and Change on the Lives of Young Children, Schools, and Neighborhoods. Board on Children, Youth and Families, Division of Behavioral and Social Sciences and Education. Washington, DC: National Academies Press.

Olsen, Edgar O. (2003). “Housing Programs for Low-Income Households.” In Means-Tested Transfer Programs in the United States. Ed. Robert A. Moffitt. U. Chicago Press. 365-442.

Polinsky, A. Mitchell, and David T. Ellwood (1979). "An empirical reconciliation of micro and grouped estimates of the demand for housing." Review of Economics and Statistics, 61(2): 199-205.

Rice, Douglas, and Barbara Sard (2009). Decade of Neglect has Weakened Federal Low-Income Housing Programs. Washington, DC: Center on Budget and Policy Priorities. Downloaded from http://www.cbpp.org/files/2-24-09hous.pdf on April 4, 2014.

Rubinowitz, Leonard S., and James E. Rosenbaum (2000). Crossing the Class and Color Lines:

From Public Housing to White Suburbia. Chicago: University of Chicago Press.

Sanbonmatsu, Lisa, Jeffrey R. Kling, Greg J. Duncan, and Jeanne Brooks-Gunn (2006).

"Neighborhoods and Academic Achievement: Results from the MTO Experiment." Journal of Human Resources, 41(4): 649-91.

Sanbonmatsu, Lisa, Jens Ludwig, Lawrence F. Katz, Lisa A. Gennetian, Greg J. Duncan, Ronald C. Kessler, Emma Adam, Thomas W. McDade, and Stacy Tessler Lindau (2011). 
Moving to Opportunity for Fair Housing Demonstration Program: Final Impacts Evaluation. Washington, DC: U.S. Department of Housing and Urban Development, Office of Policy Development and Research.

Schanzenbach, Diane W. (2007). "What Have Researchers Learned from Project STAR?" Brookings Papers on Education Policy, 205-228.

Schochet, Peter Z., John Burghardt, and Sheena McConnell (2008). "Does Job Corps Work? Impact Findings from the National Job Corps Study.” American Economic Review, 98(5): 1864-86.

Sharfstein, Joshua, Megan Sandel, Robert Kahn, and Howard Bauchner (2001). "Is Child Health at Risk While Families Wait for Housing Vouchers?" American Journal of Public Health, 91(8): 1191-93.

Shea, John (2000). “Does Parents' Money Matter?” Journal of Public Economics, 77(2): 15584.

Shonkoff, Jack P., and Deborah A. Phillips (2000). From Neurons to Neighborhoods: The Science of Early Childhood Development. National Academies Press.

Smeeding, Timothy M. (2006) "Poor people in rich nations: The United States in comparative perspective." Journal of Economic Perspectives. 20(1): 69-90.

Theunissen, Nicolet C. M., T. G. C. Vogels, H. M. Koopman, G. H. W. Verrips, K. A. H. Zwinderman, S. P. Verloove-Vanhorick, and J. M. Wit (1998). “The proxy problem: child report versus parent report in health-related quality of life research." Qualify of Life Research, 7(5): 387-97.

Westfall, Peter H., and S. Stanley Young (1993). "On adjusting P-Values for multiplicity." Biometrics, 49: 941-5. 
Wilson, William J. (1996). When Work Disappears: The World of the New Urban Poor. New York, NY: Alfred A. Knopf. 
Figure I: Budget constraint and consumption with and without housing voucher

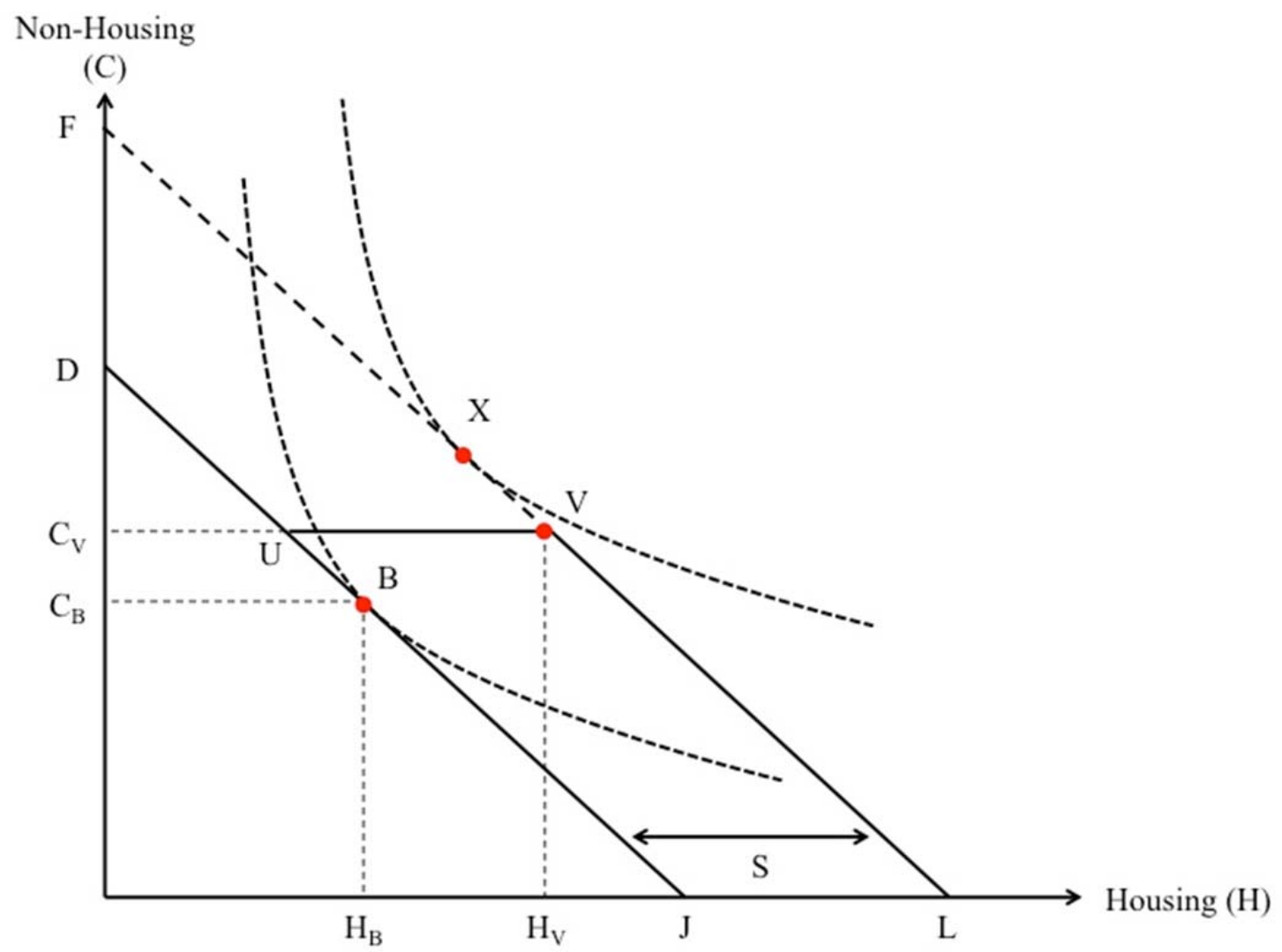

Without a housing voucher, the family's budget constraint is given by $D J$ with initial consumption bundle $B$. Receipt of a housing voucher leads to new budget constraint $D U V L$, where $\left(D-C_{V}\right)$ is the rent contribution required by the housing voucher program, $H_{V}$ is essentially the maximum rent allowable under the housing voucher program (the Fair Market Rent; in some versions of the voucher program families can lease units with higher rents but for simplicity we assume here this is a maximum rent). $V$ is the new consumption bundle for a family that uses a voucher to lease a unit with rent at the maximum allowable level, which leads to more housing consumption than a family would choose if instead given a cash transfer with the same cost to the government $(S)$. 
Figure II: Distribution of change in housing consumption among leased-up sample

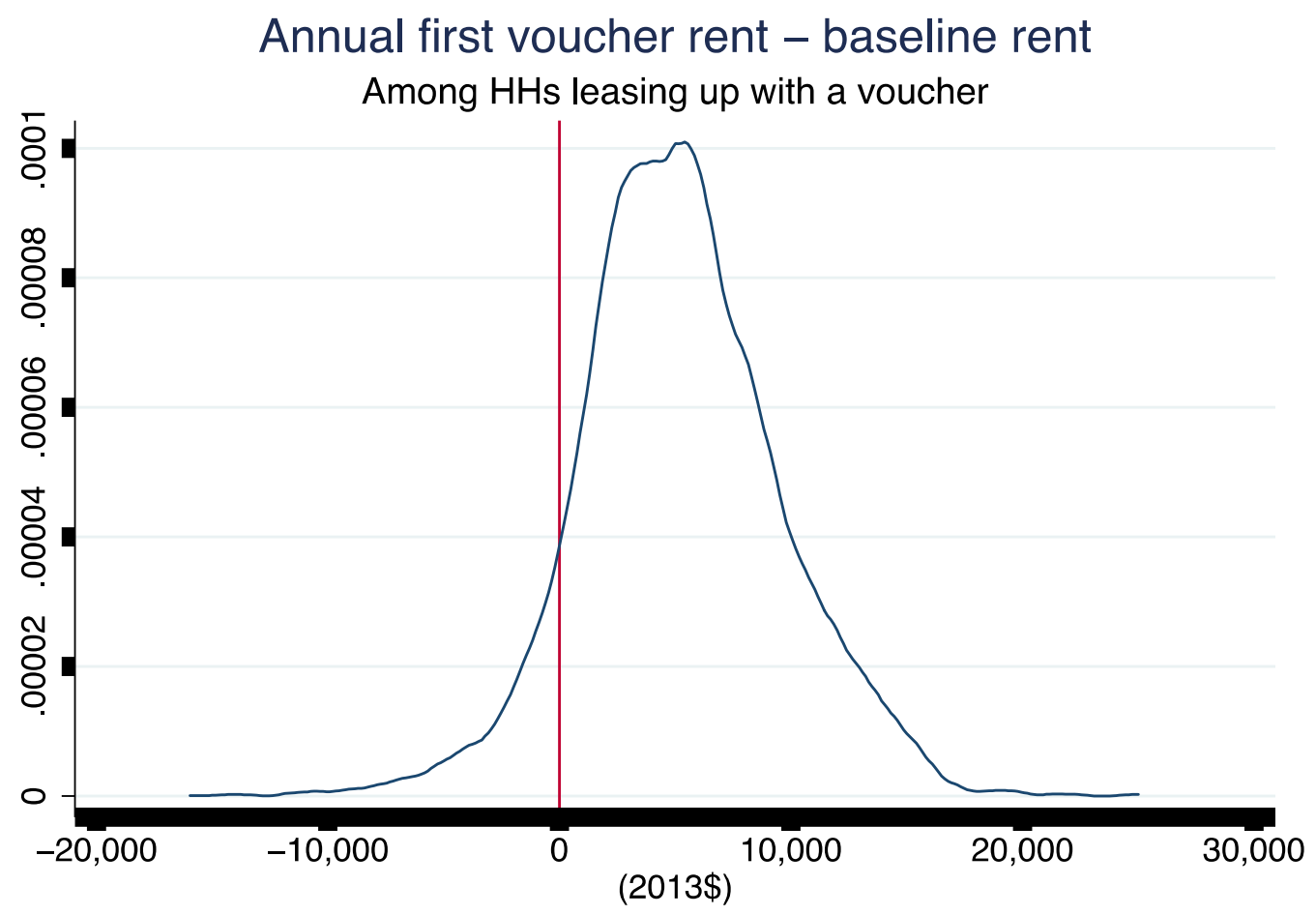

Figure shows the distribution of the change in housing consumption from receipt of a housing voucher. Baseline rent is estimated using a special tabulation of 2000 Census data from Chicago and assumes that families in our study sample have the same average rents as other, demographically-similar households in the same baseline census tracts (see Appendix D). First voucher rent is measured using HUD 50058 forms, which all families in means-tested housing programs are required to complete each year (or whenever they relocate). All figures converted to constant 2013 dollars. 
Figure III: Calculating value of cash transfer that would lead to same change in consumption of non-housing goods as families experience with a housing voucher

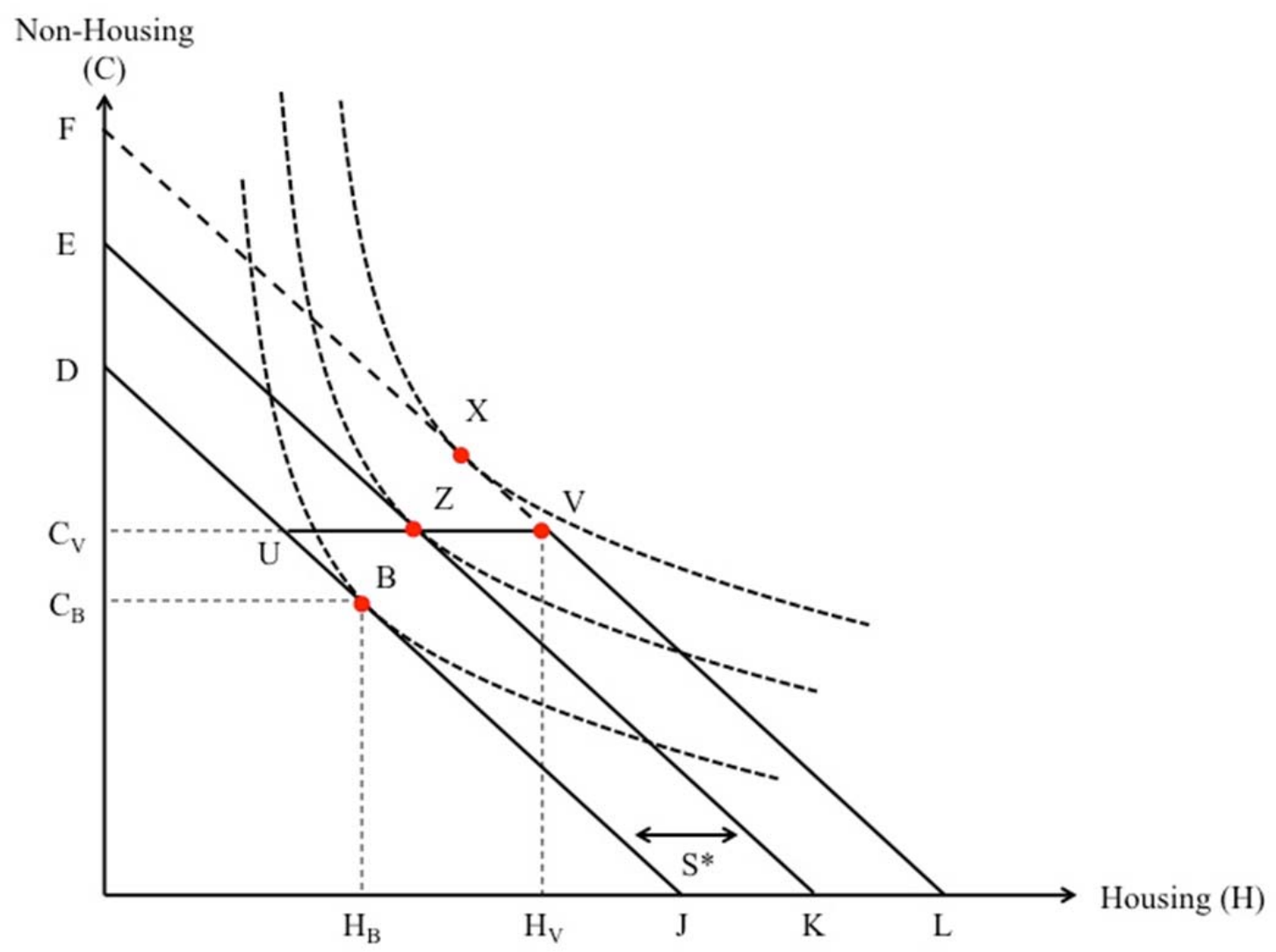

Cash transfer $S^{*}$ leads to same change in consumption of non-housing goods $\left(C_{V}-C_{B}\right)$ as families would experience if they receive a housing voucher worth $S$ to the government. One of our model specifications in the tables below assumes (conservatively) that housing consumption has no effect on children's outcomes, and uses an indicator for randomly-assigned voucher offer as an instrument for non-housing consumption $\left(S^{*}\right)$ to estimate the change in children's outcomes for a $\$ 1,000$ gain in family income. 
Figure IV: Estimated intention to treat effects on children's achievement test scores and criminal activity, by year from housing voucher offer

\section{ITT on Test Scores and Social Cost of Crime}
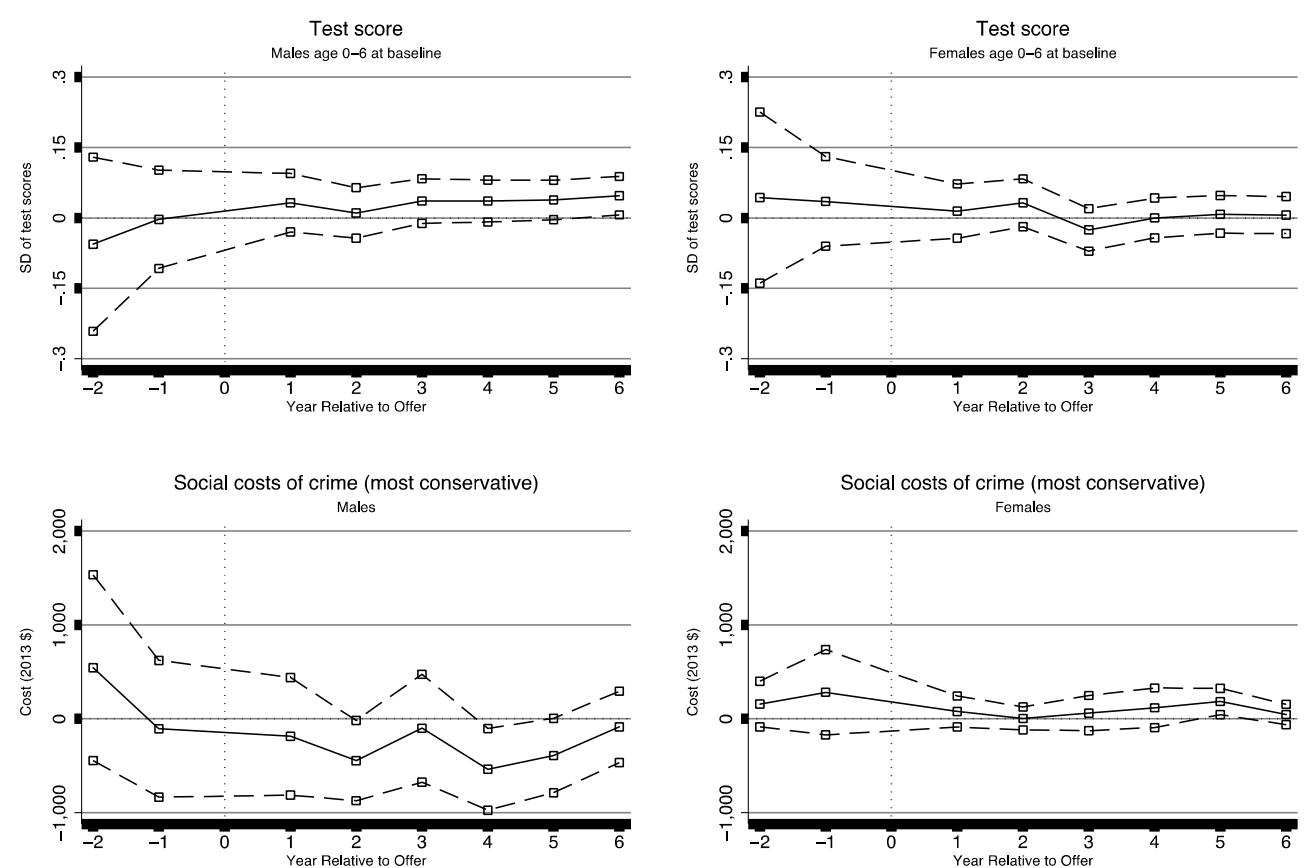

Each panel of the figure presents the results from estimating a separate regression where the dependent variable is either achievement test scores in math and reading from Chicago Public School student-level records (panels A and B) or the monetized value of the criminal activity youth commit (panels $C$ and $D$ ). The explanatory variables of interest are a series of indicator variables for whether a given child-year observation is $(\mathrm{k})$ years from when the child's family is offered a housing voucher, where $(\mathrm{k})$ takes on both positive values (post-voucher offer) and negative values (pre-voucher offer). The figures present the regression coefficients on these indicator variables, together with the $95 \%$ confidence intervals. Note that because our dataset consists of child-year observations that are all after the randomized housing voucher lottery occurred, the coefficients on prevoucher-offer years represent tests of whether there are behavioral "anticipation effects" rather than a test of whether randomization was carried out correctly. 
Figure V: Effects of Cash Transfers on Test Scores of Young Males Across Studies

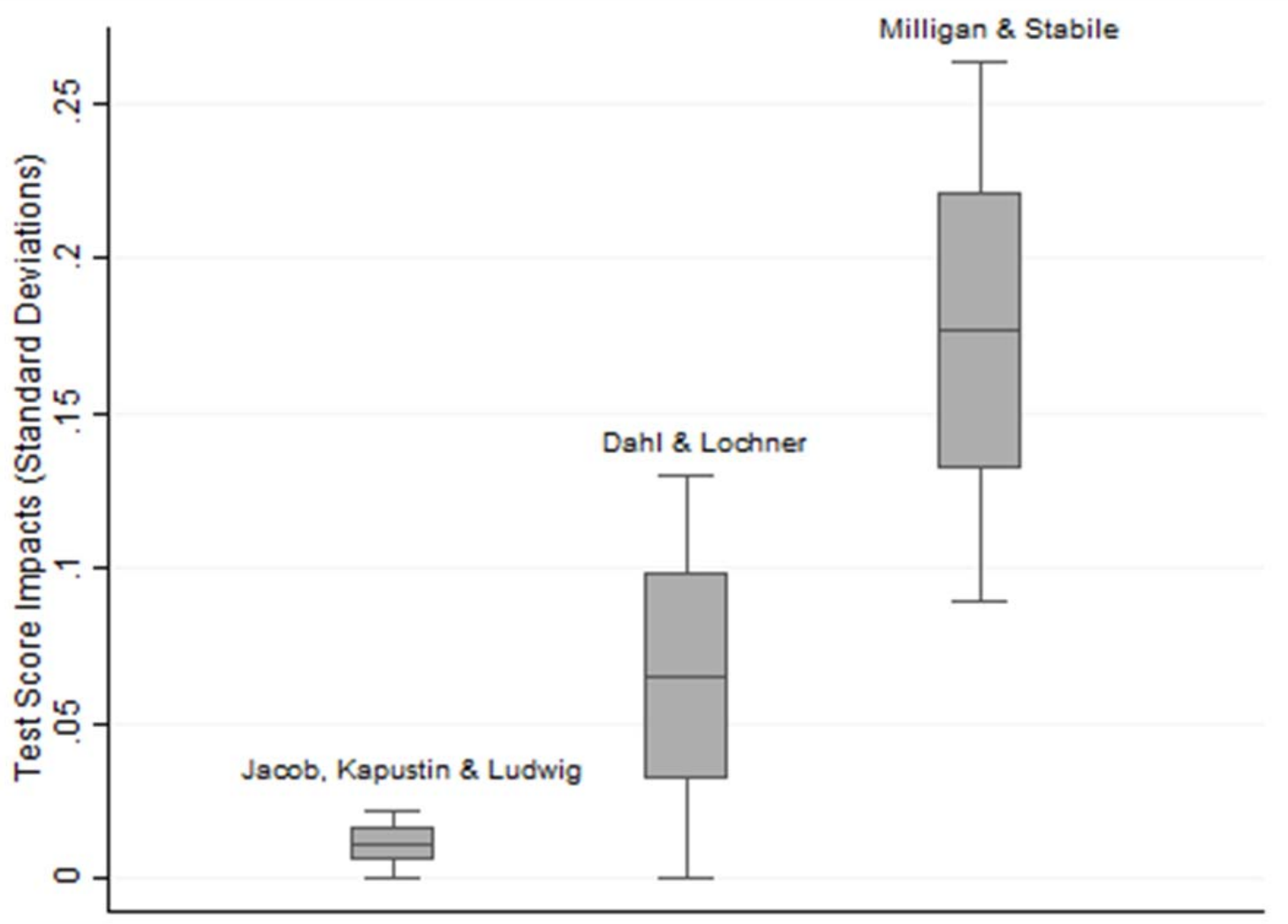

Figure reports the effects on children's achievement test scores per $\$ 1,000$ change in family income (in 2013 dollars). The estimate from Jacob, Kapustin and Ludwig is for males 0-6 at baseline taken from Table VI, column 5, using as the dependent variable an average of reading and math achievement test scores from Chicago Public Schools student-level school records. The estimate from Dahl and Lochner (2012) is also for an average of reading and math test scores, taken from their Table 6 for males (equal to 0.088 standard deviations in their paper reported in 2000 constant dollars, and equal to 0.065 when we update to 2013 dollars). Estimate from Milligan and Stabile (2011) is for math scores for males, taken from their Table 3, equal to 0.23 standard deviations in their paper for a $\$ 1,000$ change in Canadian 2004 dollars, and equal to 0.177 when we update to 2013 US dollars. 
Figure VI: Effects of Cash Transfer on High School Graduation Rates Across Studies

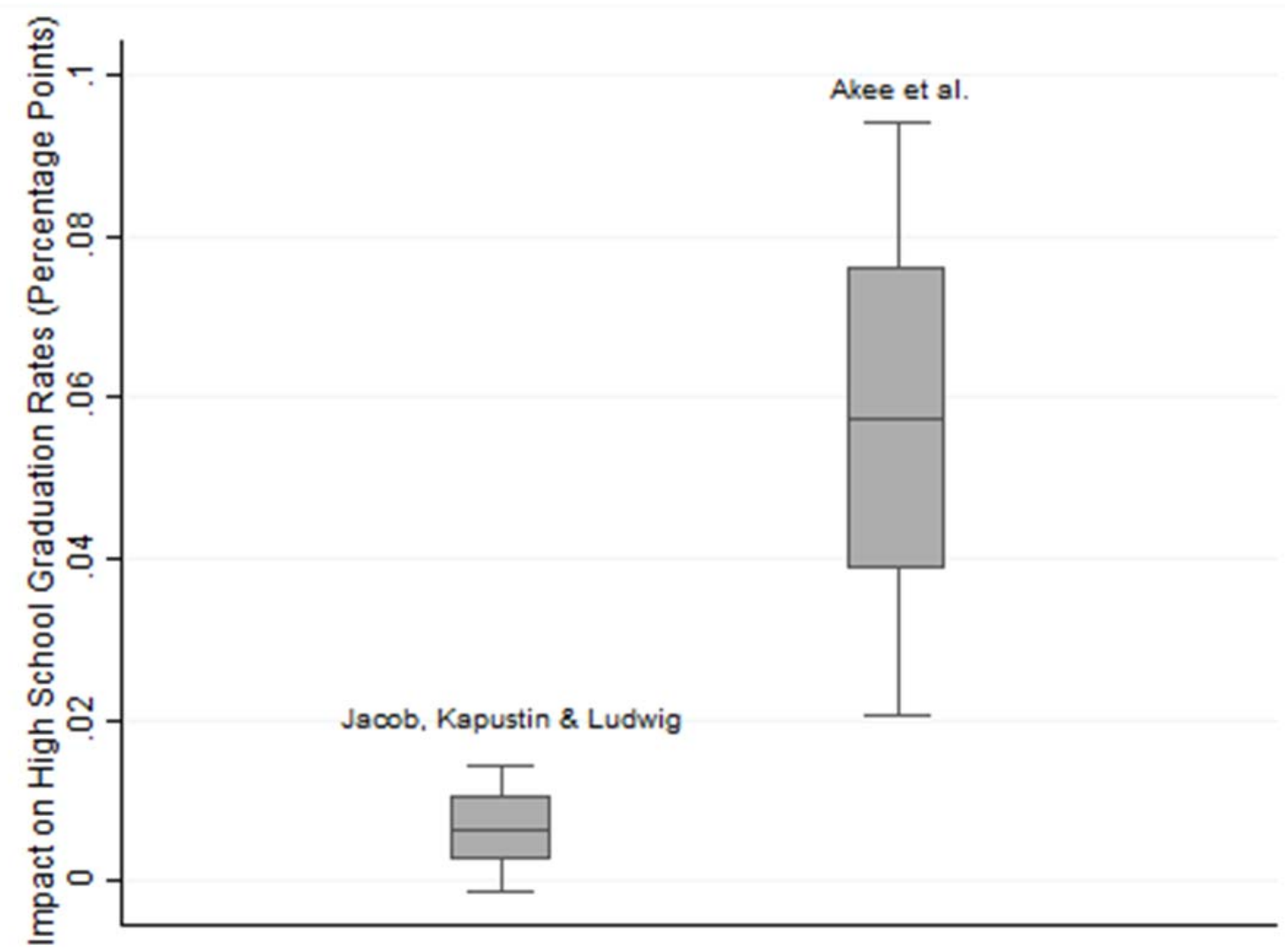

Figure reports the effects on high school graduation probabilities per $\$ 1,000$ change in family income (in 2013 dollars). The estimate from Jacob, Kapustin and Ludwig is for males 6-18 at baseline taken from Table VI, column 5, using as the dependent variable an indicator for whether the youth graduated from high school during our study period according to Chicago Public Schools student-level school records. Estimate from Akee et al. (2010) is for males is based on their Table 5, column 2; the marginal effect here corresponds to a 32 percentage point change in high school graduation rates from a $\$ 4,000$ change in family income in 1996-2002 dollars, or 8 percentage points per $\$ 1,000$. The effect equals 5.8 percentage points per $\$ 1,000$ when we update to 2013 dollars. 
Figure VII: OLS Estimate of Income-Test Score Relationship Across Studies

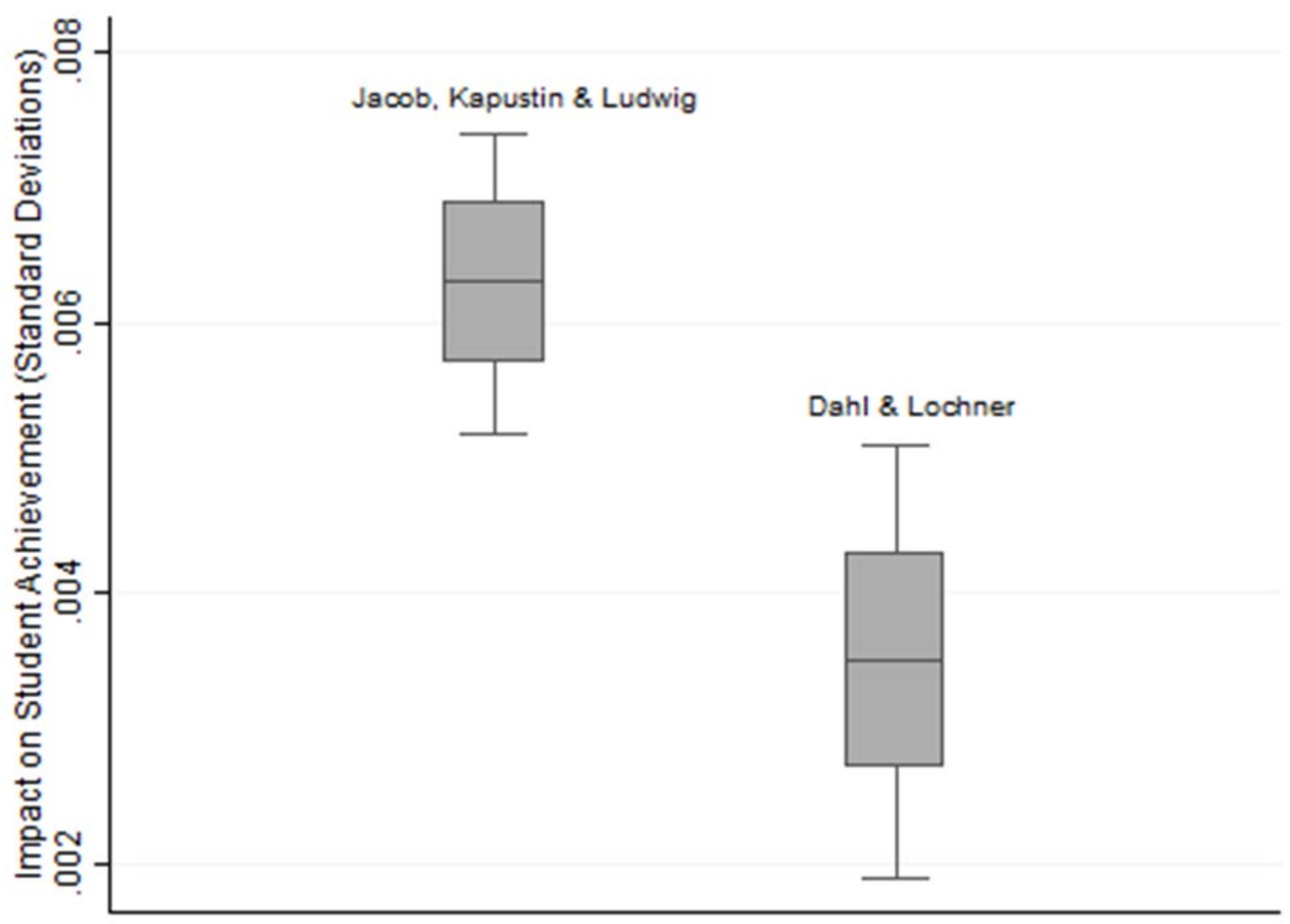

Figure reports the cross-sectional relationship between family income, measured in thousands of 2013 dollars, and children's achievement test scores. The estimate from Jacob, Kapustin and Ludwig is for a sample of all children ages 8-14 in July 1997 in households living in private market housing at baseline that participated in the lottery (including those from households with lottery numbers between 18,110 and 35,000). The dependent variable is an average of reading and math achievement test scores in the 1997-8 academic school year from Chicago Public Schools student-level school records. Family income encompasses UI earnings, tax refunds or liabilities, TANF, and food stamp benefit levels in 1996:Q3 through 1997:Q2. Additional controls include gender; indicators for having 1, 2, or 3+ siblings; race; age; household head's age; and the number of adults in the household. The resulting point estimate and standard error clustered at the household level are 0.0063 (0.0006). This attempts to replicate as closely as possible using our data the result in Dahl and Lochner (2012), Table 2, Column 1, equal to 0.0047 standard deviations per $\$ 1,000$ of income reported in 2000 constant dollars, and equal to 0.0035 standard deviations when updated to 2013 dollars. 
Figure VIII

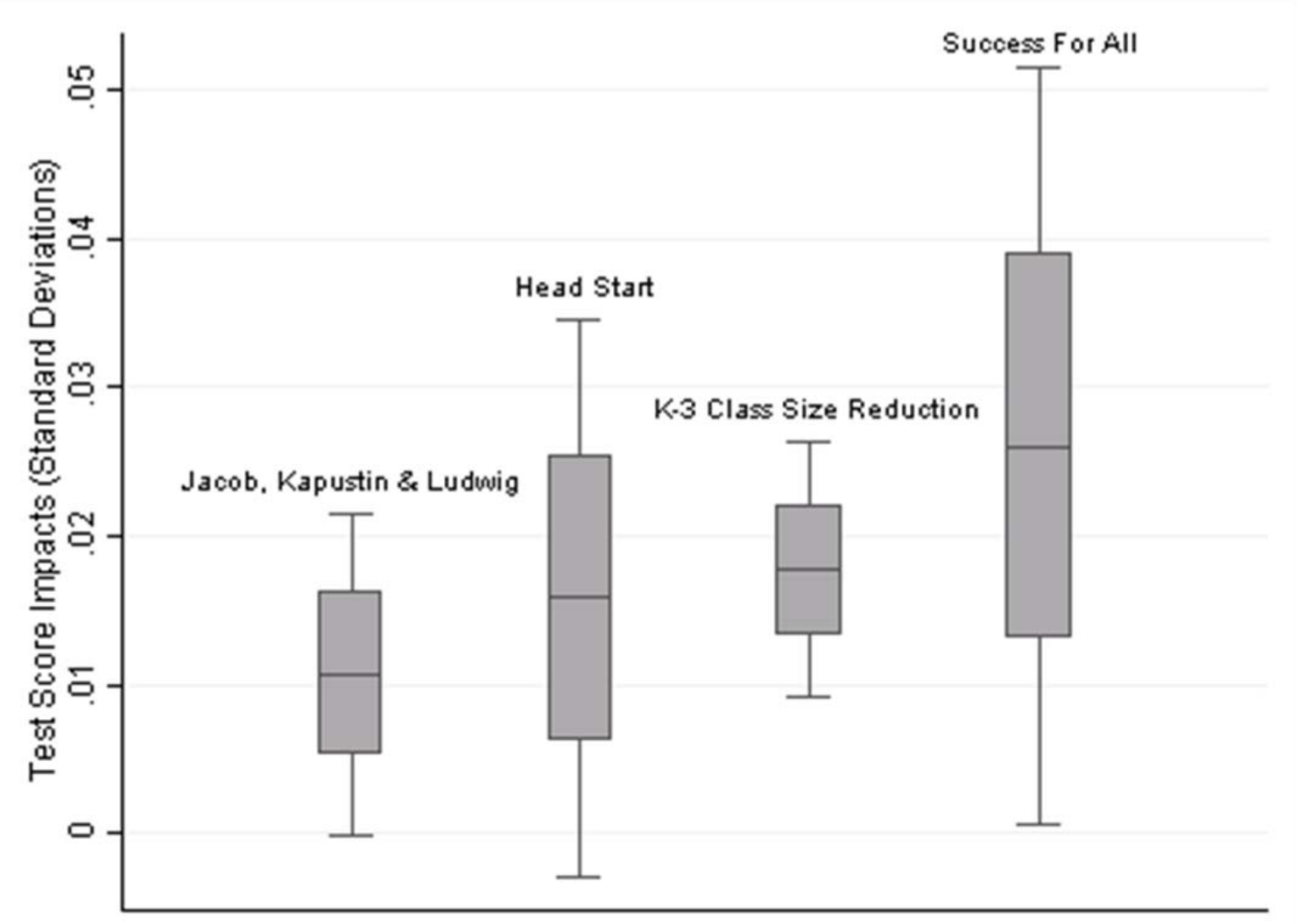

Figure reports the effects on children's achievement test scores per $\$ 1,000$ (in 2013 dollars). The estimate from Jacob, Kapustin and Ludwig is for males 0-6 at baseline taken from Table VI, column 5, using as the dependent variable an average of reading and math achievement test scores from Chicago Public Schools student-level school records. The Head Start estimate is the median TOT for 4-year olds from Ludwig and Phillips (2008), Table 1 (equal to 0.164 standard deviations in their paper per $\$ 9,000$ in 2006 dollars, and to 0.0158 standard deviations per $\$ 1,000$ in 2013 dollars). The K-3 class size reduction estimate is from the analysis of the Tennessee STAR experiment and its effect on black children in Schanzenbach (2007), Table 4 (equal to 0.242 standard deviations in the original study per $\$ 10,120$ in 2000 dollars, and to 0.018 standard deviations per $\$ 1,000$ in 2013 dollars). Finally, the Success For All estimate is the effect on math scores from Borman and Hewes (2002), Table 4 (equal to 0.036 standard deviations in their paper per $\$ 1,000$ in 2000 dollars, and to 0.027 standard deviations per $\$ 1,000$ in 2013 dollars). 


\section{Household Level \\ HHH: Male \\ HHH: Black \\ HHH: Hispanic \\ HHH: White \\ HHH: Other race \\ HHH: Has spouse}

\# Adults in Household (Based on CHAC file)

\# of kids 0-18 in $\mathrm{HH}$ (Based on CHAC file)

Age of $\mathrm{HHH}$

Indicated interest in certificate as well as voucher program

Reported receiving Supplemental Security Income (SSI) benefits

Time (in days) of application since application opened

HH total income (2013 \$) 1996:III to 1997:II

HHH income (2013 \$) 1997:II

HHH employed 1997:II

HHH receiving TANF 1997:II

HHH receiving TANF, Med, or FS 1997:II

HHH: \# of prior violent crime arrests

HHH: \# of prior property crime arrests

HHH: \# of prior drug crime arrests

$\mathrm{HHH}$ : \# of prior other crime arrests

Census tract \% black

Census tract poverty rate

Property crime rate (beat-level, per 1,000) in 1997

Violent crime rate (beat-level, per 1,000) in 1997

Monthy rent (2013 \$)

Monthly fair market rent ( $2013 \$)$

\section{Child Level}

Male

Black

Hispanic

Age

\# of prior violent crime arrests

\# of prior property crime arrests

\# of prior drug crime arrests

\# of prior other crime arrests

Enrolled in the Chicago Public Schools Pre-Lottery

Math Test Score in Year Prior to Lottery

Reading Test Score in Year Prior to Lottery

GPA in Year Prior to Lottery

\# of Absences Prior to Lottery

Fraction Black in child's school

Fraction Latino in child's school

Fraction eligible for free-lunch in child's school

Average test score in child's school

$\mathrm{N}$ (Children)

$\mathrm{N}$ (Households)

Joint test, all coefficients (including missing indicators)

Chi-squared statistic (clustering at $\mathrm{HH}$ level)

$p$-value

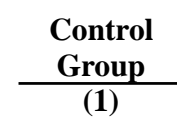

(1)

0.035

0.942

0.035

0.020

0.003

0.082

1.419

2.953

31.634

0.799

0.172

9.290

$18,938.000$

$1,934.589$

0.462

0.625

0.782

0.149

0.271

0.128

0.192

0.822

0.302

74.401

38.593

782.067

$1,316.330$

\begin{tabular}{cc} 
All & $p$-valu \\
\hline (2) & (3)
\end{tabular}

0.040

0.944

0.032

0.022

0.002

0.084

1.416

2.927

31.568

\subsection{8}

0.501

0.224

0.425

0.342

0.695

0.813

0.424

0.801

0.564

0.178

0.786

9.304

0.320

$19,084.922 \quad 0.386$

$2,007.974 \quad 0.079$

0.469

0.606

0.769

0.144

0.228

0.126

0.178

0.824

0.301

74.642

38.686

778.106

1,314.109

0.350

0.007

0.025

0.539

0.011

0.793

0.793
0.229

0.694
0.499

0.499

0.651

0.781

0.781
0.318

0.575

Treatment Group

Compliers

Non-Compliers

$*$



$* *$
$* *$

(4)

(5)

$0.024 \quad 0.062$

$0.959 \quad 0.924$

$0.025 \quad 0.041$

$0.014 \quad 0.033$

$0.002 \quad 0.002$

$0.070 \quad 0.101$

$\begin{array}{ll}1.376 & 1.470\end{array}$

$2.991 \quad 2.839$

$30.859 \quad 32.525$

$\begin{array}{ll}0.799 & 0.803\end{array}$

$0.189 \quad 0.164$

$8.985 \quad 9.732$

$18,461.211 \quad 19,925.102$

$1,718.751 \quad 2,397.575$

$0.456 \quad 0.486$

$0.669 \quad 0.522$

$0.831 \quad 0.686$

$0.149 \quad 0.137$

$0.235 \quad 0.219$

$0.124 \quad 0.129$

$\begin{array}{ll}0.178 & 0.179\end{array}$

$0.849 \quad 0.791$

$\begin{array}{ll}0.310 & 0.288\end{array}$

$\begin{array}{ll}75.087 & 74.008\end{array}$

$39.721 \quad 37.208$

777.027

$1,319.951$

779.644
$1,306.240$

0.500

0.942

0.035

8.478

0.010

0.005

0.015

0.011

0.598

$-0.244$

$-0.213$

1.518

28.921

0.848

0.108

0.855

$-0.182$

48,263

22,447

0.505

0.945

0.234

0.032

8.546

0.009

0.005

0.018

0.012

0.599

$-0.215$

$-0.189$

1.563

28.622

0.853

0.103

0.854

$-0.178$

0.340

0.208

0.201

0.654

0.895

0.097

0.762

0.824

0.068

0.126

0.129

0.666

0.220

0.151

0.654

0.445

18,347

8,560
0.506

0.959

0.025

8.247

0.008

0.004

0.016

0.009

0.604

$-0.243$

$-0.198$

1.531

28.774

0.871

0.092

0.861

$-0.187$

10,530

4,787
0.504

0.926

0.041

8.947

0.011

0.005

0.021

0.015

0.592

$-0.177$

$-0.177$

1.601

28.437

0.829

0.119

0.846

$-0.166$

7,817

3,773

Notes: Unit of analysis in the top panel is the household; in the bottom panel, the child.

*** Significant at the 1 percent level.

** Significant at the 5 percent level.

* Significant at the 10 percent level. 


\section{Full Sample}

Treatment group

Offered voucher in current or prior year

Control Mean

\# observations

Males age 0-6 at baseline

Treatment group

Offered voucher in current or prior year

Control Mean

\# observations

Males age 6-18 at baseline

Treatment group

Offered voucher in current or prior year

Control Mean

\# observations

Females age 0-6 at baseline

Treatment group

Offered voucher in current or prior year

Control Mean

\# observations

Females age 6-18 at baseline

Treatment group

Offered voucher in current or prior year

$0.4645^{* * *}$

$0.4692 * * *$

(0.0084)

0.0625

295,568

$0.4824 * * *$
$(0.0087)$

$0.5090 * * *$
$(0.0103)$

$0.4964 * * *$

0.0852

172,032

0.1030

12,288

0000

172,032

0.0000

12,288

$.5199 * * *$

(0.0060)

0.0000

932,540

0.0000

66,610

Ever

(4)

(0.0062)

$.5515 * * *$

(0.0095)

(0.0098)$$
\text { (0.0087) }
$$

$0.5036^{* * *}$

(0.0081)

$0.5255^{* * * *}$

(0.0083)

$$
\begin{aligned}
& 0.0763 \\
& 21,112
\end{aligned}
$$

0.0000

0.0000

295,568
$0.4971 * * *$

(0.0101)

$$
\begin{gathered}
0.0788 \\
167,790
\end{gathered}
$$

0.0966

11,985

$0.5088 * * *$

(0.0105)

$0.5471^{* * *}$

(0.0097)

0.0000

167,790

0.0000

11,985

(0.0101)
(0.0084)

$0.5693 * * *$

$$
\begin{gathered}
0.4800 * * * \\
(0.0087)
\end{gathered}
$$

0.0653

297,150
0.0799

21,225
$0.5284 * * *$

(0.0083)

$0.5039 * * *$

(0.0081)

0.0000

297,150
0.0000

21,225

\# observations

\footnotetext{
clustered at the household level.

*** Significant at the 1 percent level.

** Significant at the 5 percent level.

* Significant at the 10 percent level.
}

Notes: Columns 1 and 3 are ITT estimates from panel data observations. Columns 2 and 4 are ITT estimates from cross-sectional observations. Standard errors are reported in parentheses and are 


\begin{tabular}{|c|c|c|c|c|c|c|c|c|c|c|c|}
\hline \multirow[b]{3}{*}{ Gender } & \multirow[b]{3}{*}{ Baseline Age } & \multirow[b]{3}{*}{ Outcome } & \multirow[b]{3}{*}{ Individuals } & \multirow[b]{3}{*}{$\mathbf{C M}$} & \multirow[b]{3}{*}{ ITT } & \multirow[b]{3}{*}{ IV } & \multirow[b]{3}{*}{ CCM } & \multicolumn{3}{|c|}{ ITT Estimate } & \multirow[b]{3}{*}{ Obs. } \\
\hline & & & & & & & & & Adjuste & p-value & \\
\hline & & & & & & & & p-value & FWER & FDR & \\
\hline & & & $(1)$ & $(2)$ & (3) & (4) & (5) & (6) & (7) & (8) & (9) \\
\hline Male & Age 0 to 6 & Test score & 8,659 & -0.3339 & $\begin{array}{l}0.0369 * \\
(0.0190)\end{array}$ & $\begin{array}{l}0.0634 * \\
(0.0325)\end{array}$ & -0.3774 & 0.052 & 0.449 & 0.311 & 51,339 \\
\hline Male & Age 6 to 18 & Test score & 14,348 & -0.3248 & $\begin{array}{c}0.0068 \\
(0.0152)\end{array}$ & $\begin{array}{c}0.0126 \\
(0.0273)\end{array}$ & -0.3641 & 0.655 & 0.919 & 0.873 & 68,787 \\
\hline Male & Age 6 to 18 & High school graduation & 13,183 & 0.3940 & $\begin{array}{c}0.0150 \\
(0.0094)\end{array}$ & $\begin{array}{c}0.0286 \\
(0.0178)\end{array}$ & 0.4124 & 0.109 & 0.650 & 0.328 & 13,183 \\
\hline Male & All & Soc. costs, most conservative & 33,400 & $3,084.2100$ & $\begin{array}{c}-160.6255 \\
(98.2894)\end{array}$ & $\begin{array}{c}-344.0462^{*} \\
(206.0899)\end{array}$ & $3,481.5526$ & 0.102 & 0.650 & 0.328 & 283,091 \\
\hline Male & Age 0 to 6 & Inpatient or emergency claim & 9,538 & 0.2449 & $\begin{array}{l}-0.0012 \\
(0.0063)\end{array}$ & $\begin{array}{l}-0.0014 \\
(0.0114)\end{array}$ & 0.2421 & 0.852 & 0.919 & 0.920 & 52,378 \\
\hline Male & Age 6 to 18 & Inpatient or emergency claim & 12,526 & 0.2471 & $\begin{array}{l}-0.0059 \\
(0.0060)\end{array}$ & $\begin{array}{l}-0.0105 \\
(0.0112)\end{array}$ & 0.2547 & 0.324 & 0.896 & 0.556 & 56,480 \\
\hline Female & Age 0 to 6 & Test score & 8,488 & -0.1446 & $\begin{array}{c}0.0019 \\
(0.0183)\end{array}$ & $\begin{array}{c}0.0029 \\
(0.0316)\end{array}$ & -0.1511 & 0.919 & 0.919 & 0.920 & 52,107 \\
\hline Female & Age 6 to 18 & Test score & 14,855 & -0.1479 & $\begin{array}{c}0.0168 \\
(0.0143)\end{array}$ & $\begin{array}{c}0.0300 \\
(0.0273)\end{array}$ & -0.2082 & 0.240 & 0.880 & 0.556 & 73,389 \\
\hline Female & Age 6 to 18 & High school graduation & 13,792 & 0.5766 & $\begin{array}{c}0.0101 \\
(0.0094)\end{array}$ & $\begin{array}{c}0.0190 \\
(0.0176)\end{array}$ & 0.5846 & 0.279 & 0.892 & 0.556 & 13,792 \\
\hline Female & All & Soc. costs, most conservative & 33,210 & 573.6593 & $\begin{array}{l}60.8371 * * \\
(30.0558)\end{array}$ & $\begin{array}{c}121.0684 * \\
(63.1189)\end{array}$ & 634.7744 & 0.043 & 0.425 & 0.311 & 284,057 \\
\hline Female & Age 0 to 6 & Inpatient or emergency claim & 9,379 & 0.2119 & $\begin{array}{c}0.0018 \\
(0.0062)\end{array}$ & $\begin{array}{c}0.0032 \\
(0.0113)\end{array}$ & 0.2202 & 0.767 & 0.919 & 0.920 & 50,549 \\
\hline Female & Age 6 to 18 & Inpatient or emergency claim & 16,050 & 0.3702 & $\begin{array}{c}0.0025 \\
(0.0056)\end{array}$ & $\begin{array}{c}0.0047 \\
(0.0108)\end{array}$ & 0.3823 & 0.653 & 0.919 & 0.873 & 75,526 \\
\hline
\end{tabular}

\footnotetext{
Notes: Unit of observation is the person-year for all outcomes, except high school graduation which is a person-level cross-section. CM = control mean.

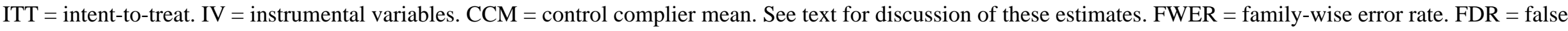
discovery rate. Standard errors are reported in parentheses and are clustered at the household level.

** Significant at the 5 percent level.

* Significant at the 10 percent level.
} 


\begin{tabular}{|c|c|c|c|c|c|c|c|c|c|c|c|}
\hline & \multicolumn{6}{|c|}{ 1997-2005 Addresses } & \multicolumn{5}{|c|}{2012 Address, 2009 Outcomes } \\
\hline & Individuals & $\mathbf{C M}$ & ITT & IV & CCM & Obs. & Individuals & $\mathbf{C M}$ & ITT & IV & $\mathbf{C C M}$ \\
\hline & (1) & (2) & (3) & (4) & (5) & (6) & $(7)$ & (8) & (9) & (10) & (11) \\
\hline Has Address on File & 6,509 & 0.897 & $\begin{array}{c}0.0067 \\
(0.0082)\end{array}$ & $\begin{array}{c}0.0141 \\
(0.0173)\end{array}$ & 0.891 & 214,797 & 6,493 & 0.863 & $\begin{array}{l}-0.0117 \\
(0.0168)\end{array}$ & $\begin{array}{l}-0.0241 \\
(0.0346)\end{array}$ & 0.896 \\
\hline Miles from Baseline Address & & & & & & & 5,437 & 63.243 & $\begin{array}{c}9.1904 \\
(11.6729)\end{array}$ & $\begin{array}{c}18.4862 \\
(23.5552)\end{array}$ & 34.647 \\
\hline Living in IL & 6,509 & 0.956 & $\begin{array}{c}0.0041 \\
(0.0072)\end{array}$ & $\begin{array}{c}0.0085 \\
(0.0151)\end{array}$ & 0.972 & 192,862 & 5,586 & 0.862 & $\begin{array}{c}0.0085 \\
(0.0169)\end{array}$ & $\begin{array}{c}0.0171 \\
(0.0339)\end{array}$ & 0.909 \\
\hline Fraction of Quarters Outside IL & 6,509 & 0.0471 & $\begin{array}{l}-0.0064 \\
(0.0071)\end{array}$ & $\begin{array}{c}-0.0132 \\
(0.0146)\end{array}$ & 0.0307 & 6,509 & & & & & \\
\hline Living in Cook County, IL & & & & & & & 5,586 & 0.796 & $\begin{array}{c}0.0145 \\
(0.0193)\end{array}$ & $\begin{array}{c}0.0292 \\
(0.0387)\end{array}$ & 0.852 \\
\hline Poverty Rate $>20 \%{ }^{1,2}$ & 6,433 & 0.655 & $\begin{array}{l}-0.0088 \\
(0.0176)\end{array}$ & $\begin{array}{l}-0.0184 \\
(0.0362)\end{array}$ & 0.712 & 184,355 & 4,461 & 0.688 & $\begin{array}{l}-0.0374 \\
(0.0248)\end{array}$ & $\begin{array}{l}-0.0698 \\
(0.0461)\end{array}$ & 0.703 \\
\hline Poverty Rate ${ }^{1,2}$ & 6,433 & 0.273 & $\begin{array}{c}0.0039 \\
(0.0055)\end{array}$ & $\begin{array}{c}0.0075 \\
(0.0112)\end{array}$ & 0.274 & 184,355 & 4,461 & 0.289 & $\begin{array}{l}-0.0076 \\
(0.0080)\end{array}$ & $\begin{array}{l}-0.0142 \\
(0.0150)\end{array}$ & 0.292 \\
\hline Fraction Black $^{1,2}$ & 6,433 & 0.794 & $\begin{array}{c}0.0012 \\
(0.0084)\end{array}$ & $\begin{array}{c}0.0023 \\
(0.0172)\end{array}$ & 0.837 & 184,463 & 4,461 & 0.760 & $\begin{array}{l}-0.0011 \\
(0.0155)\end{array}$ & $\begin{array}{l}-0.0020 \\
(0.0290)\end{array}$ & 0.789 \\
\hline Social Capital $^{1,3}$ & 6,038 & 3.495 & $\begin{array}{l}-0.0056 \\
(0.0057)\end{array}$ & $\begin{array}{l}-0.0109 \\
(0.0114)\end{array}$ & 3.501 & 164,284 & 3,659 & 3.776 & $\begin{array}{c}0.0187 \\
(0.0137)\end{array}$ & $\begin{array}{c}0.0345 \\
(0.0253)\end{array}$ & 3.769 \\
\hline Collective Efficacy ${ }^{1,3}$ & 6,038 & 3.761 & $\begin{array}{c}-0.0158 * * \\
(0.0078)\end{array}$ & $\begin{array}{c}-0.0312 * * \\
(0.0155)\end{array}$ & 3.772 & 164,284 & 3,659 & 3.502 & $\begin{array}{c}0.0177 * \\
(0.0096)\end{array}$ & $\begin{array}{l}0.0326^{*} \\
(0.0177)\end{array}$ & 3.491 \\
\hline Violent Crime Rate (per 1,000$)^{4}$ & 6,038 & 17.633 & $\begin{array}{l}-0.0896 \\
(0.3026)\end{array}$ & $\begin{array}{l}-0.1920 \\
(0.5998)\end{array}$ & 17.865 & 164,277 & 3,658 & 25.142 & $\begin{array}{c}0.1358 \\
(0.6984)\end{array}$ & $\begin{array}{c}0.2508 \\
(1.2904)\end{array}$ & 24.964 \\
\hline Property Crime Rate (per 1,000$)^{4}$ & 6,038 & 75.479 & $\begin{array}{c}-3.1948 * * * \\
(0.9911)\end{array}$ & $\begin{array}{c}-6.2988 * * * \\
(1.9753)\end{array}$ & 77.120 & 164,277 & 3,658 & 60.185 & $\begin{array}{c}0.5016 \\
(1.3479)\end{array}$ & $\begin{array}{c}0.9263 \\
(2.4904)\end{array}$ & 59.530 \\
\hline
\end{tabular}

Notes: Unit of observation in columns 1-5 (with the exception of "Fraction of Quarters Outside IL") is the person-quarter. Unit of observation in columns 7-11 is the person.

Standard errors are reported in parentheses and are clustered at the household level.

${ }^{1}$ Measured at the Census tract level.

${ }^{2}$ Data from the decennial 1990 and 2000 censuses and the American Community Surveys for 2005-9 (interpolating values for inter-censal years).

${ }^{3}$ Data from the Project on Human Development in Chicago Neighborhoods (PHCDN) Community Survey.

${ }^{4}$ Data from annual beat-level crime panel from the Chicago Police Department.

*** Significant at the 1 percent level.

** Significant at the 5 percent level.

* Significant at the 10 percent level. 
Effect of Voucher Offer (ITT)

\begin{tabular}{c}
\hline Males \\
\hline Age 0-6 Age 6-18
\end{tabular}

\begin{tabular}{cc}
\multicolumn{2}{c}{ Females } \\
\hline Age 0-6 & Age 6-18 \\
\hline (3) & (4)
\end{tabular}

Ever Enrolled in CPS during 1998-2011

(1)

(2)

(3)

(4)

$\begin{array}{cccc}-0.0003 & -0.0003 & 0.0004 & 0.0014 \\ (0.0017) & (0.0020) & (0.0014) & (0.0019) \\ {[0.845]} & {[0.812]} & {[0.843]} & {[0.820]} \\ 12,288 & 21,112 & 11,985 & 21,225\end{array}$

Ever Left CPS (Moved or Enrolled in Private)

$\begin{array}{cccc}-0.0399 * * * & -0.0115^{*} & -0.0225 * * & -0.0117 * * \\ (0.0092) & (0.0061) & (0.0095) & (0.0059) \\ {[0.278]} & {[0.223]} & {[0.266]} & {[0.201]} \\ 12,288 & 21,112 & 11,985 & 21,225\end{array}$

Enrolled in CPS in Current Academic Year

$\begin{array}{cc}0.0328 * * * & 0.0068 * * \\ (0.0067) & (0.0032) \\ {[0.505]} & {[0.324]} \\ 172,032 & 295,568\end{array}$

$0.0203 * * * \quad 0.0151 * * *$

$(0.0068) \quad(0.0031)$

[0.509] [0.334]

$172,032 \quad 295,568$

$167,790 \quad 297,150$

Tested in Current Academic Year

$\begin{array}{cccc}0.0277 * * * & 0.0052 * & 0.0239 * * * & 0.0130 * * * \\ (0.0056) & (0.0027) & (0.0057) & (0.0027) \\ {[0.299]} & {[0.235]} & {[0.311]} & {[0.250]} \\ 172,032 & 295,568 & 167,790 & 297,150\end{array}$

Ever Enrolled in Medicaid during 2000-2008

$\begin{array}{cccc}0.0008 & 0.0077 & 0.0025 & 0.0096 \\ (0.0091) & (0.0076) & (0.0094) & (0.0070) \\ {[0.776]} & {[0.591]} & {[0.783]} & {[0.754]} \\ 12,288 & 21,112 & 11,985 & 21,225\end{array}$

Enrolled in Medicaid in Current Academic Year

$\begin{array}{cc}0.0108 & 0.0113^{* *} \\ (0.0086) & (0.0052) \\ {[0.471]} & {[0.295]} \\ 110,592 & 190,008\end{array}$

$0.0145^{*}$

$0.0112 *$

$(0.0088) \quad(0.0058)$

110,592

[0.466]

[0.394]

$107,865 \quad 191,025$

Notes: Order of results: ITT estimate; standard error (parentheses); control mean (brackets); number of observations. Standard errors are clustered at the household level.

*** Significant at the 1 percent level.

** Significant at the 5 percent level.

* Significant at the 10 percent level. 


\begin{tabular}{|c|c|c|c|c|c|c|c|}
\hline \multirow{3}{*}{ Gender } & \multirow[b]{2}{*}{ Baseline Age } & \multirow[b]{2}{*}{ Outcome } & \multirow{3}{*}{$\begin{array}{c}\text { Individuals } \\
(1)\end{array}$} & \multirow{3}{*}{$\frac{\mathbf{C M}}{(2)}$} & \multicolumn{3}{|c|}{ Implied Voucher Value } \\
\hline & & & & & $\mathbf{S}$ & $\mathbf{S}^{*}$ & $\Delta \mathrm{C}$ \\
\hline & & & & & (3) & (4) & (5) \\
\hline Male & Age 0 to 6 & Test score & 8,659 & -0.3339 & $\begin{array}{l}0.0050 * \\
(0.0026)\end{array}$ & $\begin{array}{l}0.0084 * \\
(0.0043)\end{array}$ & $\begin{array}{l}0.0107 * \\
(0.0055)\end{array}$ \\
\hline Male & Age 6 to 18 & Test score & 14,348 & -0.3248 & $\begin{array}{c}0.0010 \\
(0.0022)\end{array}$ & $\begin{array}{c}0.0019 \\
(0.0042)\end{array}$ & $\begin{array}{c}0.0021 \\
(0.0047)\end{array}$ \\
\hline Male & Age 6 to 18 & High school graduation & 13,183 & 0.3940 & $\begin{array}{c}0.0029 \\
(0.0018)\end{array}$ & $\begin{array}{c}0.0065 \\
(0.0041)\end{array}$ & $\begin{array}{c}0.0064 \\
(0.0040)\end{array}$ \\
\hline Male & All & Soc. costs, most conservative & 33,400 & $3,084.2100$ & $\begin{array}{l}-27.2071 * \\
(16.4252)\end{array}$ & $\begin{array}{l}-58.5617 * \\
(35.5156)\end{array}$ & $\begin{array}{l}-60.4924 * \\
(36.5396)\end{array}$ \\
\hline Male & Age 0 to 6 & Inpatient or emergency claim & 9,538 & 0.2449 & $\begin{array}{l}-0.0001 \\
(0.0009)\end{array}$ & $\begin{array}{l}-0.0002 \\
(0.0015)\end{array}$ & $\begin{array}{l}-0.0003 \\
(0.0019)\end{array}$ \\
\hline Male & Age 6 to 18 & Inpatient or emergency claim & 12,526 & 0.2471 & $\begin{array}{l}-0.0009 \\
(0.0009)\end{array}$ & $\begin{array}{l}-0.0017 \\
(0.0018)\end{array}$ & $\begin{array}{l}-0.0019 \\
(0.0020)\end{array}$ \\
\hline Female & Age 0 to 6 & Test score & 8,488 & -0.1446 & $\begin{array}{c}0.0003 \\
(0.0025)\end{array}$ & $\begin{array}{c}0.0004 \\
(0.0042)\end{array}$ & $\begin{array}{c}0.0007 \\
(0.0054)\end{array}$ \\
\hline Female & Age 6 to 18 & Test score & 14,855 & -0.1479 & $\begin{array}{c}0.0024 \\
(0.0021)\end{array}$ & $\begin{array}{c}0.0046 \\
(0.0042)\end{array}$ & $\begin{array}{c}0.0052 \\
(0.0047)\end{array}$ \\
\hline Female & Age 6 to 18 & High school graduation & 13,792 & 0.5766 & $\begin{array}{c}0.0020 \\
(0.0018)\end{array}$ & $\begin{array}{c}0.0045 \\
(0.0042)\end{array}$ & $\begin{array}{c}0.0044 \\
(0.0041)\end{array}$ \\
\hline Female & All & Soc. costs, most conservative & 33,210 & 573.6593 & $\begin{array}{c}9.8595 * * \\
(5.0053)\end{array}$ & $\begin{array}{c}21.5006 * * \\
(10.9255)\end{array}$ & $\begin{array}{c}22.0343 * * \\
(11.1743)\end{array}$ \\
\hline Female & Age 0 to 6 & Inpatient or emergency claim & 9,379 & 0.2119 & $\begin{array}{c}0.0003 \\
(0.0009)\end{array}$ & $\begin{array}{c}0.0004 \\
(0.0015)\end{array}$ & $\begin{array}{c}0.0006 \\
(0.0019)\end{array}$ \\
\hline Female & Age 6 to 18 & Inpatient or emergency claim & 16,050 & 0.3702 & $\begin{array}{c}0.0004 \\
(0.0009)\end{array}$ & $\begin{array}{c}0.0008 \\
(0.0019)\end{array}$ & $\begin{array}{c}0.0008 \\
(0.0019)\end{array}$ \\
\hline
\end{tabular}

\footnotetext{
Notes: Unit of observation is the person-year for all outcomes, except high school graduation which is a person-level cross-section. IV estimates shown are re-scaled by the implied value of the voucher--S, $\mathrm{S}^{*}$, or $\Delta \mathrm{C}$--in thousands of $2013 \$$. $\mathrm{S}$ is the total cost to the government of the housing voucher subsidy, equal to $\$ 12,501$ on average for our study sample. $\mathrm{S}^{*}$ is the cash transfer that would generate the same increase in non-housing consumption as does a housing voucher, equal to $\$ 6,377$ on average for our study sample; see text for calculation. $\Delta \mathrm{C}$ is the increase in non-housing consumption from receiving a housing voucher, equal to $\$ 5,653$ on average for our study sample. Standard errors are reported in parentheses and are clustered at the household level.

** Significant at the 5 percent level.

* Significant at the 10 percent level.
} 
Table VII: Estimated Effects of Cash Transfers on Education, Criminal Behavior, and Health for Inframarginal Households

\begin{tabular}{|c|c|c|c|c|c|c|c|c|}
\hline \multirow{3}{*}{ Gender } & \multirow{3}{*}{ Baseline Age } & \multirow[b]{2}{*}{ Outcome } & \multicolumn{3}{|c|}{ Baseline Rent > FMR - \$50 } & \multicolumn{3}{|c|}{ Baseline Rent > FMR } \\
\hline & & & Individuals & $\mathbf{C M}$ & Subsidy $=\Delta C$ & Individuals & $\mathbf{C M}$ & Subsidy $=\Delta \mathrm{C}$ \\
\hline & & & (1) & (2) & (3) & (4) & (5) & $(6)$ \\
\hline Male & Age 0 to 6 & Test score & 490 & -0.2424 & $\begin{array}{c}0.0145 \\
(0.0116)\end{array}$ & 338 & -0.2519 & $\begin{array}{c}0.0166 \\
(0.0147)\end{array}$ \\
\hline Male & Age 6 to 18 & Test score & 720 & -0.2616 & $\begin{array}{l}-0.0007 \\
(0.0096)\end{array}$ & 498 & -0.2725 & $\begin{array}{l}-0.0080 \\
(0.0109)\end{array}$ \\
\hline Male & Age 6 to 18 & High school graduation & 661 & 0.4134 & $\begin{array}{c}0.0013 \\
(0.0101)\end{array}$ & 461 & 0.4387 & $\begin{array}{c}0.0050 \\
(0.0125)\end{array}$ \\
\hline Male & All & Soc. costs, most conservative & 1,752 & $2,925.5025$ & $\begin{array}{l}-78.6808 \\
(67.1669)\end{array}$ & 1,221 & $2,859.1061$ & $\begin{array}{c}-152.7635^{* *} \\
(69.3798)\end{array}$ \\
\hline Male & Age 0 to 6 & Inpatient or emergency claim & 543 & 0.2613 & $\begin{array}{l}-0.0018 \\
(0.0040)\end{array}$ & 382 & 0.2676 & $\begin{array}{l}-0.0063 \\
(0.0043)\end{array}$ \\
\hline Male & Age 6 to 18 & Inpatient or emergency claim & 633 & 0.2367 & $\begin{array}{c}0.0008 \\
(0.0035)\end{array}$ & 441 & 0.2204 & $\begin{array}{c}0.0075 \\
(0.0046)\end{array}$ \\
\hline Female & Age 0 to 6 & Test score & 484 & -0.0146 & $\begin{array}{l}-0.0045 \\
(0.0119)\end{array}$ & 328 & 0.0490 & $\begin{array}{l}-0.0255^{*} \\
(0.0143)\end{array}$ \\
\hline Female & Age 6 to 18 & Test score & 755 & -0.0668 & $\begin{array}{l}-0.0158 \\
(0.0127)\end{array}$ & 543 & -0.0849 & $\begin{array}{l}-0.0240^{*} \\
(0.0144)\end{array}$ \\
\hline Female & Age 6 to 18 & High school graduation & 702 & 0.6357 & $\begin{array}{l}-0.0052 \\
(0.0095)\end{array}$ & 505 & 0.6589 & $\begin{array}{l}-0.0065 \\
(0.0108)\end{array}$ \\
\hline Female & All & Soc. costs, most conservative & 1,757 & 642.5750 & $\begin{array}{c}5.8208 \\
(26.5180)\end{array}$ & 1,220 & 593.6785 & $\begin{array}{c}7.3000 \\
(31.1000)\end{array}$ \\
\hline Female & Age 0 to 6 & Inpatient or emergency claim & 532 & 0.2426 & $\begin{array}{c}0.0010 \\
(0.0035)\end{array}$ & 360 & 0.2446 & $\begin{array}{l}-0.0007 \\
(0.0043)\end{array}$ \\
\hline Female & Age 6 to 18 & Inpatient or emergency claim & 776 & 0.3716 & $\begin{array}{l}-0.0006 \\
(0.0043)\end{array}$ & 537 & 0.3824 & $\begin{array}{l}-0.0069 \\
(0.0045)\end{array}$ \\
\hline
\end{tabular}

Notes: Unit of observation is the person-year for all outcomes, except high school graduation which is a person-level cross-section. IV estimates shown are re-scaled by the non-housing value of the voucher $(\Delta \mathrm{C})$ in thousands of $2013 \$$. Standard errors are reported in parentheses and are clustered at the household level.

** Significant at the 5 percent level.

* Significant at the 10 percent level. 


\begin{tabular}{|c|c|c|c|c|c|c|}
\hline Outcome & Individuals & $\mathbf{C M}$ & ITT & IV & $\mathbf{C C M}$ & Obs. \\
\hline & (1) & (2) & (3) & (4) & (5) & (6) \\
\hline \multicolumn{7}{|l|}{ Males age 0-6 at baseline } \\
\hline Missing school demographics & 10,374 & 0.0159 & $\begin{array}{c}0.0011 \\
(0.0017)\end{array}$ & $\begin{array}{c}0.0019 \\
(0.0030)\end{array}$ & 0.0133 & 92,043 \\
\hline Fraction black & 10,341 & 0.8495 & $\begin{array}{c}0.0015 \\
(0.0046)\end{array}$ & $\begin{array}{c}0.0028 \\
(0.0081)\end{array}$ & 0.8679 & 90,561 \\
\hline Fraction Latino & 10,341 & 0.1173 & $\begin{array}{l}-0.0002 \\
(0.0038)\end{array}$ & $\begin{array}{l}-0.0003 \\
(0.0066)\end{array}$ & 0.1037 & 90,561 \\
\hline Fraction with subsidized lunch & 10,341 & 0.8698 & $\begin{array}{c}0.0009 \\
(0.0018)\end{array}$ & $\begin{array}{c}0.0016 \\
(0.0031)\end{array}$ & 0.8637 & 90,561 \\
\hline Fraction special education & 10,341 & 0.1286 & $\begin{array}{c}-0.0028 * * * \\
(0.0010)\end{array}$ & $\begin{array}{c}-0.0048 * * * \\
(0.0017)\end{array}$ & 0.1335 & 90,561 \\
\hline Total enrollment & 10,341 & 768.2978 & $\begin{array}{c}17.2501 * * \\
(7.0679)\end{array}$ & $\begin{array}{c}30.8500 * * \\
(12.3332)\end{array}$ & 744.2949 & 90,561 \\
\hline Average test score & 10,341 & -0.1981 & $\begin{array}{c}0.0035 \\
(0.0058)\end{array}$ & $\begin{array}{c}0.0062 \\
(0.0100)\end{array}$ & -0.2274 & 90,561 \\
\hline \multicolumn{7}{|l|}{ Males age 6-18 at baseline } \\
\hline Missing school demographics & 17,168 & 0.0274 & $\begin{array}{l}-0.0009 \\
(0.0024)\end{array}$ & $\begin{array}{l}-0.0018 \\
(0.0045)\end{array}$ & 0.0267 & 102,794 \\
\hline Fraction black & 17,005 & 0.8281 & $\begin{array}{c}0.0005 \\
(0.0043)\end{array}$ & $\begin{array}{c}0.0007 \\
(0.0079)\end{array}$ & 0.8464 & 99,998 \\
\hline Fraction Latino & 17,005 & 0.1275 & $\begin{array}{l}-0.0011 \\
(0.0034)\end{array}$ & $\begin{array}{l}-0.0019 \\
(0.0063)\end{array}$ & 0.1181 & 99,998 \\
\hline Fraction with subsidized lunch & 17,005 & 0.8528 & $\begin{array}{l}-0.0010 \\
(0.0019)\end{array}$ & $\begin{array}{l}-0.0020 \\
(0.0034)\end{array}$ & 0.8485 & 99,998 \\
\hline Fraction special education & 17,005 & 0.1433 & $\begin{array}{l}-0.0010 \\
(0.0012)\end{array}$ & $\begin{array}{l}-0.0019 \\
(0.0021)\end{array}$ & 0.1534 & 99,998 \\
\hline Total enrollment & 17,005 & 965.2989 & $\begin{array}{c}2.2003 \\
(8.4074)\end{array}$ & $\begin{array}{c}4.7429 \\
(15.4892)\end{array}$ & $1,004.0393$ & 99,998 \\
\hline Average test score & 17,005 & -0.2109 & $\begin{array}{c}0.0006 \\
(0.0052)\end{array}$ & $\begin{array}{c}0.0019 \\
(0.0095)\end{array}$ & -0.2515 & 99,998 \\
\hline \multicolumn{7}{|l|}{ Females age 0-6 at baseline } \\
\hline Missing school demographics & 10,096 & 0.0127 & $\begin{array}{l}-0.0006 \\
(0.0012)\end{array}$ & $\begin{array}{l}-0.0010 \\
(0.0022)\end{array}$ & 0.0119 & 90,004 \\
\hline Fraction black & 10,053 & 0.8502 & $\begin{array}{c}0.0075 \\
(0.0048)\end{array}$ & $\begin{array}{c}0.0134 \\
(0.0084)\end{array}$ & 0.8678 & 88,883 \\
\hline Fraction Latino & 10,053 & 0.1159 & $\begin{array}{l}-0.0050 \\
(0.0040)\end{array}$ & $\begin{array}{l}-0.0090 \\
(0.0070)\end{array}$ & 0.1012 & 88,883 \\
\hline Fraction with subsidized lunch & 10,053 & 0.8677 & $\begin{array}{c}0.0006 \\
(0.0019)\end{array}$ & $\begin{array}{c}0.0010 \\
(0.0034)\end{array}$ & 0.8609 & 88,883 \\
\hline Fraction special education & 10,053 & 0.1245 & $\begin{array}{l}-0.0010 \\
(0.0009)\end{array}$ & $\begin{array}{l}-0.0018 \\
(0.0015)\end{array}$ & 0.1282 & 88,883 \\
\hline Total enrollment & 10,053 & 787.9906 & $\begin{array}{l}-3.2201 \\
(7.1769)\end{array}$ & $\begin{array}{c}-6.2892 \\
(12.6614)\end{array}$ & 796.8033 & 88,883 \\
\hline Average test score & 10,053 & -0.1800 & $\begin{array}{l}-0.0000 \\
(0.0061)\end{array}$ & $\begin{array}{l}-0.0002 \\
(0.0108)\end{array}$ & -0.1955 & 88,883 \\
\hline
\end{tabular}




\begin{tabular}{|c|c|c|c|c|c|c|}
\hline Outcome & Individuals & $\mathbf{C M}$ & ITT & IV & CCM & Obs. \\
\hline & (1) & (2) & (3) & (4) & (5) & (6) \\
\hline \multicolumn{7}{|l|}{ Females age 6-18 at baseline } \\
\hline Missing school demographics & 17,336 & 0.0159 & $\begin{array}{c}-0.0008 \\
(0.0017)\end{array}$ & $\begin{array}{l}-0.0017 \\
(0.0033)\end{array}$ & 0.0182 & 104,514 \\
\hline Fraction black & 17,274 & 0.8281 & $\begin{array}{l}-0.0051 \\
(0.0044)\end{array}$ & $\begin{array}{l}-0.0100 \\
(0.0086)\end{array}$ & 0.8454 & 102,860 \\
\hline Fraction Latino & 17,274 & 0.1259 & $\begin{array}{c}0.0067^{*} \\
(0.0036)\end{array}$ & $\begin{array}{c}0.0134 * \\
(0.0070)\end{array}$ & 0.1127 & 102,860 \\
\hline Fraction with subsidized lunch & 17,274 & 0.8564 & $\begin{array}{c}0.0004 \\
(0.0017)\end{array}$ & $\begin{array}{c}0.0010 \\
(0.0034)\end{array}$ & 0.8493 & 102,860 \\
\hline Fraction special education & 17,274 & 0.1364 & $\begin{array}{c}0.0012 \\
(0.0010)\end{array}$ & $\begin{array}{c}0.0023 \\
(0.0019)\end{array}$ & 0.1468 & 102,860 \\
\hline Total enrollment & 17,274 & $1,005.9582$ & $\begin{array}{l}-0.6216 \\
(9.1214)\end{array}$ & $\begin{array}{c}-1.7242 \\
(17.7645)\end{array}$ & $1,061.2455$ & 102,860 \\
\hline Average test score & 17,274 & -0.1789 & $\begin{array}{l}-0.0045 \\
(0.0054)\end{array}$ & $\begin{array}{l}-0.0089 \\
(0.0105)\end{array}$ & -0.2128 & 102,860 \\
\hline
\end{tabular}

$\overline{\overline{\text { Notes: }} \text { Unit of observation is the person-year for all outcomes. Standard errors are reported in parentheses and are }}$ at the household level.

*** Significant at the 1 percent level.

** Significant at the 5 percent level.

* Significant at the 10 percent level. 


\begin{tabular}{|c|c|c|c|c|c|c|}
\hline Outcome & Individuals & $\mathbf{C M}$ & ITT & IV & CCM & Obs. \\
\hline & (1) & (2) & (3) & (4) & $(5)$ & (6) \\
\hline \multicolumn{7}{|l|}{ Males age 0-6 at baseline } \\
\hline School moves & 9,888 & 0.2585 & $\begin{array}{c}0.0074 \\
(0.0045)\end{array}$ & $\begin{array}{l}0.0132 * \\
(0.0078)\end{array}$ & 0.2633 & 80,983 \\
\hline School moves (involuntary) & 9,888 & 0.1146 & $\begin{array}{c}0.0014 \\
(0.0019)\end{array}$ & $\begin{array}{c}0.0026 \\
(0.0033)\end{array}$ & 0.1088 & 80,983 \\
\hline School moves (voluntary) & 9,888 & 0.1439 & $\begin{array}{c}0.0060 \\
(0.0040)\end{array}$ & $\begin{array}{c}0.0105 \\
(0.0070)\end{array}$ & 0.1545 & 80,983 \\
\hline Miles from baseline address to school & 9,730 & 2.9078 & $\begin{array}{c}0.2053 * * \\
(0.0827)\end{array}$ & $\begin{array}{c}0.3609 * * \\
(0.1437)\end{array}$ & 2.8576 & 86,748 \\
\hline Miles from current address to school & 8,243 & 2.7543 & $\begin{array}{c}0.1204 \\
(0.0930)\end{array}$ & $\begin{array}{c}0.2093 \\
(0.1596)\end{array}$ & 2.7041 & 60,057 \\
\hline Missing school move data & 9,964 & 0.0223 & $\begin{array}{c}0.0008 \\
(0.0006)\end{array}$ & $\begin{array}{c}0.0015 \\
(0.0011)\end{array}$ & 0.0020 & 82,806 \\
\hline Missing baseline address to school data & 10,374 & 0.0575 & $\begin{array}{c}0.0015 \\
(0.0015)\end{array}$ & $\begin{array}{c}0.0028 \\
(0.0027)\end{array}$ & 0.0501 & 92,043 \\
\hline Missing current address to school data & 10,374 & 0.3414 & $\begin{array}{c}0.0274 * * * \\
(0.0099)\end{array}$ & $\begin{array}{c}0.0486 * * * \\
(0.0172)\end{array}$ & 0.3199 & 92,043 \\
\hline \multicolumn{7}{|l|}{ Males age 6-18 at baseline } \\
\hline School moves & 16,710 & 0.2740 & $\begin{array}{c}0.0062 \\
(0.0040)\end{array}$ & $\begin{array}{c}0.0115 \\
(0.0073)\end{array}$ & 0.2874 & 98,682 \\
\hline School moves (involuntary) & 16,710 & 0.1289 & $\begin{array}{c}0.0014 \\
(0.0020)\end{array}$ & $\begin{array}{c}0.0021 \\
(0.0038)\end{array}$ & 0.1529 & 98,682 \\
\hline School moves (voluntary) & 16,710 & 0.1451 & $\begin{array}{c}0.0048 \\
(0.0036)\end{array}$ & $\begin{array}{c}0.0094 \\
(0.0066)\end{array}$ & 0.1344 & 98,682 \\
\hline Miles from baseline address to school & 16,110 & 2.6321 & $\begin{array}{c}0.3251 * * * \\
(0.0707)\end{array}$ & $\begin{array}{c}0.5820 * * * \\
(0.1286)\end{array}$ & 2.6727 & 96,226 \\
\hline Miles from current address to school & 13,197 & 2.2226 & $\begin{array}{c}0.3793 * * * \\
(0.0882)\end{array}$ & $\begin{array}{c}0.6959 * * * \\
(0.1634)\end{array}$ & 2.1350 & 68,459 \\
\hline Missing school move data & 16,834 & 0.0060 & $\begin{array}{c}0.0001 \\
(0.0005)\end{array}$ & $\begin{array}{c}0.0002 \\
(0.0010)\end{array}$ & 0.0014 & 99,284 \\
\hline Missing baseline address to school data & 17,168 & 0.0648 & $\begin{array}{c}0.0018 \\
(0.0022)\end{array}$ & $\begin{array}{c}0.0033 \\
(0.0040)\end{array}$ & 0.0550 & 102,794 \\
\hline Missing current address to school data & 17,168 & 0.3336 & $\begin{array}{c}0.0080 \\
(0.0093)\end{array}$ & $\begin{array}{c}0.0170 \\
(0.0169)\end{array}$ & 0.3456 & 102,794 \\
\hline \multicolumn{7}{|l|}{ Females age 0-6 at baseline } \\
\hline School moves & 9,575 & 0.2497 & $\begin{array}{c}0.0108 * * \\
(0.0045)\end{array}$ & $\begin{array}{c}0.0196 * * \\
(0.0079)\end{array}$ & 0.2514 & 79,257 \\
\hline School moves (involuntary) & 9,575 & 0.1158 & $\begin{array}{c}-0.0004 \\
(0.0019)\end{array}$ & $\begin{array}{c}-0.0003 \\
(0.0034)\end{array}$ & 0.1085 & 79,257 \\
\hline School moves (voluntary) & 9,575 & 0.1339 & $\begin{array}{c}0.0112 * * * \\
(0.0040)\end{array}$ & $\begin{array}{c}0.0199 * * * \\
(0.0070)\end{array}$ & 0.1429 & 79,257 \\
\hline Miles from baseline address to school & 9,472 & 2.8560 & $\begin{array}{c}0.2469 * * * \\
(0.0789)\end{array}$ & $\begin{array}{c}0.4419 * * * \\
(0.1380)\end{array}$ & 2.9567 & 85,273 \\
\hline Miles from current address to school & 8,105 & 2.7384 & $\begin{array}{l}0.1675^{*} \\
(0.0909)\end{array}$ & $\begin{array}{l}0.3129 * \\
(0.1640)\end{array}$ & 2.8259 & 58,877 \\
\hline Missing school move data & 9,648 & 0.0223 & $\begin{array}{c}0.0003 \\
(0.0006)\end{array}$ & $\begin{array}{c}0.0006 \\
(0.0011)\end{array}$ & 0.0046 & 81,055 \\
\hline Missing baseline address to school data & 10,096 & 0.0541 & $\begin{array}{l}-0.0010 \\
(0.0009)\end{array}$ & $\begin{array}{l}-0.0017 \\
(0.0015)\end{array}$ & 0.0446 & 90,004 \\
\hline
\end{tabular}




\begin{tabular}{|c|c|c|c|c|c|c|}
\hline Outcome & Individuals & CM & ITT & IV & CCM & Obs. \\
\hline & (1) & $(2)$ & (3) & (4) & (5) & (6) \\
\hline Missing current address to school data & 10,096 & 0.3455 & $\begin{array}{c}0.0081 \\
(0.0096)\end{array}$ & $\begin{array}{c}0.0152 \\
(0.0170)\end{array}$ & 0.3582 & 90,004 \\
\hline \multicolumn{7}{|l|}{ Females age 6-18 at baseline } \\
\hline School moves & 17,048 & 0.2633 & $\begin{array}{c}0.0155^{* * *} \\
(0.0040)\end{array}$ & $\begin{array}{c}0.0309 * * * \\
(0.0078)\end{array}$ & 0.2667 & 101,039 \\
\hline School moves (involuntary) & 17,048 & 0.1262 & $\begin{array}{c}0.0021 \\
(0.0019)\end{array}$ & $\begin{array}{c}0.0037 \\
(0.0038)\end{array}$ & 0.1475 & 101,039 \\
\hline School moves (voluntary) & 17,048 & 0.1372 & $\begin{array}{c}0.0134 * * * \\
(0.0037)\end{array}$ & $\begin{array}{c}0.0272 * * * \\
(0.0071)\end{array}$ & 0.1192 & 101,039 \\
\hline Miles from baseline address to school & 16,450 & 2.6933 & $\begin{array}{c}0.1637 * * \\
(0.0739)\end{array}$ & $\begin{array}{c}0.3252 * * \\
(0.1426)\end{array}$ & 2.9493 & 99,203 \\
\hline Miles from current address to school & 13,425 & 2.1993 & $\begin{array}{c}0.2345^{* * *} \\
(0.0850)\end{array}$ & $\begin{array}{c}0.4612 * * * \\
(0.1646)\end{array}$ & 2.3640 & 69,667 \\
\hline Missing school move data & 17,143 & 0.0053 & $\begin{array}{c}0.0001 \\
(0.0005)\end{array}$ & $\begin{array}{c}0.0001 \\
(0.0011)\end{array}$ & 0.0009 & 101,590 \\
\hline Missing baseline address to school data & 17,336 & 0.0489 & $\begin{array}{c}-0.0009 \\
(0.0013)\end{array}$ & $\begin{array}{l}-0.0020 \\
(0.0025)\end{array}$ & 0.0651 & 104,514 \\
\hline Missing current address to school data & 17,336 & 0.3340 & $\begin{array}{c}-0.0047 \\
(0.0093)\end{array}$ & $\begin{array}{c}-0.0068 \\
(0.0178)\end{array}$ & 0.3616 & 104,514 \\
\hline
\end{tabular}

$\overline{\text { Notes: Unit of observation is the person-year for all outcomes. Standard errors are reported in parentheses and are cluster }}$ at the household level.

*** Significant at the 1 percent level.

** Significant at the 5 percent level.

* Significant at the 10 percent level. 